\title{
Extreme Rainfall Mechanisms Exhibited by Typhoon Morakot (2009)
}

\author{
Ching-Yuang Huang ${ }^{1,2, *}$, Chan-Seng Wong ${ }^{1}$, and Tien-Chiang Yeh ${ }^{3}$ \\ ${ }^{1}$ Department of Atmospheric Sciences, National Central University, Jhongli, Taiwan \\ ${ }^{2}$ Taiwan Typhoon and Flood Research Institute, Taichung, Taiwan \\ ${ }^{3}$ Central Weather Bureau, Taipei, Taiwan
}

Received 12 January 2011, accepted 1 July 2011

\begin{abstract}
Moderate Typhoon Morakot (2009) became the most catastrophic typhoon in Taiwan on record. The MM5 numerical experiments with and without bogus data assimilation (BDA) were used to investigate the extreme rainfall mechanisms in Taiwan associated with the westbound typhoon. The BDA, based on 4DVAR, helps MM5 to maintain a more consolidated typhoon vortex and better predict the observed track after landfall, thus producing realistic extreme rainfall (about $2400 \mathrm{~mm}$ ) at the southern and Central Mountain Range (CMR) of Taiwan. Severe rainfall in Taiwan is dominated by the CMR that hence modulates rainfall predictability.

Model analyses indicate that the synoptic environment provides low-level preconditioning with large convective available energy (CAPE) in the southwest monsoon conveying belt in conjunction with the cyclonic Morakot. When Morakot passed slowly over north Taiwan, the developing Tropical Storm Goni, originating west of Hong Kong, facilitated the moist southwesterly flow to converge with the northerly cyclonic flow of Morakot. These processes contributed to enhanced rainfall in south Taiwan. In an experiment whereby the Goni vortex was initially deactivated by BDA, the southwesterly prevailing flow, southwest of Taiwan, weakened considerably and shifted southward at a later time, resulting in one-third reduction in total accumulated rainfall in south Taiwan. Conversely, total accumulated rainfall in Taiwan is greatly reduced when the initial Morakot vortex is deactivated. Removal of Taiwan topography results in a significant reduction in total accumulated rainfall by more than $50 \%$, due to lack of orographic lift by the CMR.
\end{abstract}

Key words: Typhoon Morakot, MM5 4DVAR, BDA, CMR

Citation: Huang, C. Y., C. S. Wong, and T. C. Yeh, 2011: Extreme rainfall mechanisms exhibited by Typhoon Morakot (2009). Terr. Atmos. Ocean. Sci., 22, 613-632, doi: 10.3319/TAO.2011.07.01.01(TM)

\section{INTRODUCTION}

In August 2009, moderate Typhoon Morakot brought more than 3000-mm accumulated rainfall in Taiwan over four days which broke historical records over the past 60 years. Such extreme rainfall caused massive landslides, debris/mudflow and overrun flooding $3-6 \mathrm{~m}$ deep over many coastal villages in southern Taiwan. A total of 651 persons lost their lives due to a variety of effects from Morakot. More than three hundred people at the banks of a mountain river were buried by the flash mud slide in the early morning of the $9^{\text {th }}$ of August 2009. This catastrophic flood was denominated as the " 88 Flood" since the flash flood emerged rapidly on the $8^{\text {th }}$ of August (Father's Day in Taiwan). Ironi-

\footnotetext{
* Corresponding author

E-mail:hcy@atm.ncu.edu.tw
}

cally, 2009 was a relatively dry year for East Asia, and Taiwan would have been very short of rainfall if Morakot had not made landfall, according to the special report from the National Science Council of Taiwan (Hsu et al. 2010). The official track prediction from the Central Weather Bureau (CWB) in Taiwan was reasonably good compared to most performances at other operation centers. However, the associated 72-h accumulated rainfall in south Taiwan before landfall was 600 to $1000 \mathrm{~mm}$, which appeared to be significantly under-predicted.

Taiwan is located near the edge of the western North Pacific and experiences 3.7 typhoons yearly on average. The Central Mountain Range (CMR) in Taiwan, which is higher than $2 \mathrm{~km}$ on average, plays an effective role in intercepting the typhoon's abundant moisture on steep windward slopes. The natural environment and manmade structures in 
Taiwan have often suffered very much from violent wind and severe orographic rainfall associated with impinging typhoons (Wu and Kuo 1999). In response to the complex orographic effects of the CMR, a typhoon vortex will often be changed significantly and the associated internal eyewall may become highly asymmetric making the track evolution rather complicated and thus more difficult to predict. This uncertainty in the structural changes in the vortex core greatly affects the skill of typhoon prediction with regard to the locations of intense rainfall rates and the amounts of accumulated rainfall.

The interaction between the typhoon vortex and the CMR which cause track deviations and different rainfall activities has long been a challenging problem tackled by numerous studies (e.g., Chang 1982; Bender et al. 1987; Yeh and Elsberry 1993a, b; Lin et al. 2002, 2005; Wu et al. 2002, 2009; Chiao and Lin 2003; Huang et al. 2005; Jian and Wu 2008; Yang et al. 2008, 2011; Chien and Kuo 2011). The intense flow associated with a typhoon striking Taiwan tends to produce persistent heavy rains over the steep windward slopes, a situation favorable for a possible "terrain-locking" mechanism that somewhat reduces the difficulty in obtaining rainfall predictability (Wu et al. 2002, 2009; Huang et al. 2005; Lin et al. 2005). A fundamental problem in regard to a typhoon's rainfall in Taiwan for CWB forecasters therefore is determining how to provide a more accurate track prediction since a small track error in landfall position often leads to significant misplacement and deviation of intense wind and heavy rainfall.

Since typhoon/hurricane movements may also be influenced by the structure of the initial vortex, proper vortex bogussing often is necessary in order to provide a more realistic cyclone picture for improvement in track prediction (Leslie and Holland 1995). Among many studies, different methods have been used to improve the initial typhoon vortex, e.g., the vortex surgery method (Kurihara et al. 1993, 1995), re-implantation of the model integrated vortex (e.g., Liu et al. 1997), a powerful physical initialization scheme with complementary observations (Krishnamurti et al. 1993), the inclusion of a Rankine vortex in the background analysis or by assimilation of 3DVAR (Xiao et al. 2006, 2009; Chen 2007; Chou et al. 2008; Wang et al. 2008; Hsiao et al. 2010), bogus data assimilation (BDA) using 4DVAR (Xiao et al. 2000; Zou and Xiao 2000; Pu and Braun 2001; Park and Zou 2004; Wu et al. 2006), or the recently developed method using an Ensemble Kalman Filter (EnKF) (e.g., Chen and Snyder 2007; Wu et al. 2010a; Yen et al. 2011). The insertion of a stronger vortex may help improve cyclone intensity forecasting since the model initial cyclone better captures the observed intensity and position. The skill in tropical cyclone track forecasting has been considerably improved at the CWB as a new bogus vortex has been implanted into the operational typhoon model (e.g., Hsiao et al. 2010). However, typhoon intensity forecasts, even using the sophisticated 4DVAR with BDA, are still not always skillful, partly due to the uncertainty in vortex bogussing with some semi-empirical parameters and partly due to the response of model dynamics to the bogus vortex.

Although typhoon/hurricane intensity forecasting is a challenging task, accurately predicting the associated accumulated rainfall in Taiwan may still be possible if the track can be well predicted by the model. For example, Wu et al. (2002) used the MM5 model at a $2.2 \mathrm{~km}$ horizontal resolution to simulate the extremely intense rainfall rate of the westbound Super-Typhoon Herb (1996), which produced a daily rainfall of $1987 \mathrm{~mm}$ over the central CMR, a recordbreaking amount in Taiwan. Although the rainfall maximum for Herb was still under-predicted as $1199 \mathrm{~mm}$, the major rainfall distributions in Taiwan agreed well with the observations. Another example was the severe rainfall of more than $1000 \mathrm{~mm}$ associated with the moderate southwest bound Typhoon Nari (2001). This typhoon has been well simulated by MM5 at a high horizontal resolution (e.g., Huang et al. 2005; Yang et al. 2008, 2011). Recently, Wu et al. (2009) successfully simulated an intense rainfall event associated with the northeast bound Typhoon Babs (1998) as its outer cyclonic flow confronted the winter monsoon flow in north Taiwan.

The westbound Typhoon Morakot in August 2009, which brought an extremely large amount of rainfall (around $3000 \mathrm{~mm}$ ), also offers a great opportunity to examine the model predictability of island rainfall and the possible mechanisms responsible for such extreme rainfall. For this case, the synoptic environment exhibits some favorable conditions with the active East Asian summer monsoon trough providing intense southwesterly flow southwest of Taiwan. Warm ocean eddies in Morakot's path also provide certain favorable conditions for enhancing Morakot's convection (Lin et al. 2011). After the typhoon's passage over Taiwan, such intense southwesterly flow may be an important factor in enhancing the total accumulated rainfall in Taiwan which has also been exhibited by other typhoons, such as the northbound Typhoon Mindulle (2004) (Chien et al. 2008; Lee et al. 2008). Using the WRF model (Skamarock et al. 2005), Ge et al. (2010) highlighted the importance of the steep CMR in producing the extreme rainfall in south Taiwan. Similarly, using the high-resolution WRF, the extreme rainfall associated with Morakot has been well simulated (Tao et al. 2011). In a review of the current achievements for Morakot's prediction, Wu et al. (2010b) discussed many important factors (including physical processes, numerical methods, interaction with the underlying ocean, data assimilation, ensemble forecasting, etc.) all affecting the prediction of tropical cyclone track and intensity. These high demands certainly pose a big challenge on official CWB forecasting as well as for academic investigation.

In this study, the regional model MM5 was used to investigate the severe rainfall associated with Morakot and 
several possible contributors to such rainfall in Taiwan during its vigorous activity time based on a series of sensitivity experiments with BDA. This study complements other model studies with regard to severe rainfall in Taiwan (e.g., Hendricks et al. 2011; Tao et al. 2011; Yen et al. 2011). Many issues remain worthy of exploring specifically the relative contributions of several factors (cf. the CMR, Morakot typhoon, Goni vortex, and southwest monsoon) to the accumulated rainfall in Taiwan. The model and numerical experiments are introduced in section 2. Descriptions of the synoptic conditions and the observed rainfall in Taiwan for the Morakot event are given in section 3, followed by the model results in section 4. Possible mechanisms responsible for such extreme rainfall in Taiwan are discussed in section 5. Finally, conclusions are given in section 6 .

\section{MODELS AND EXPERIMENT DESIGNS}

In this study, the regional model MM5 was used to investigate Typhoon Morakot. The MM5 is the fifth-generation Pennsylvania State University - National Center for Atmospheric Research (PSU-NCAR) mesoscale model version 3.7 (Dudhia et al. 2005). The MM5 model's physics and parameterization schemes used in this study are given in Table 1. Three nested domains at a horizontal resolution of 45-, 15- and 5-km, respectively, are employed with the model top of $20 \mathrm{hPa}$. There are 34 layers (35 full-sigma vertical levels) used in the model experiments described in Table 2. The initial conditions and boundary conditions were taken from the NCEP Global Forecast System (GFS) analyses and predictions (at horizontal resolution of $1^{\circ}$ by $1^{\circ}$ ), respectively. Morakot made landfall in east Taiwan at 1550 UTC on the $7^{\text {th }}$ of August 2009. The model forecast thus was chosen to start from 0000 UTC on the $6^{\text {th }}$ of August 2009 and integrated for $72 \mathrm{~h}$ within which period most rainfall in Taiwan was produced.

Bogus data assimilation (BDA) was performed to enhance the initial vortex intensity (Zou and Xiao 2000). The MM5 4DVAR (Zou et al. 1997) was adopted to assimilate a bogus vortex at the observed typhoon center with the sealevel central pressure of $960 \mathrm{hPa}$ and the radius of the 34knot wind speed $(300 \mathrm{~km})$ for Morakot as estimated by the Japanese Meteorological Agency (JMA). Radial distributions of sea-level pressure and tangential wind in a gradientwind balance inside the bogus vortex are specified following Park and Zou (2004). A three-dimensional (3-D) tangential wind at 15 vertical levels was then introduced as the surface tangential wind multiplied by different weighting coefficients that gradually decrease with height. To account for the effect of surface friction, a weaker radial wind component near the surface was also included. These three kinds of bogus observations (i.e., the sea-level pressure and wind, the near-surface radial wind, and the 3-D tangential wind) were assimilated by the MM5 4DVAR every three minutes in a time window of half an hour. The BDA was performed only for the outer domain at a $45-\mathrm{km}$ horizontal resolution. The vortex structure in the second domain (15-km resolution) was specified by nesting the results of the outer domain. This BDA approach allows for the development of asymmetric flow as well as vertical circulation for the implanted vortex, as illustrated by Park and Zou (2004).

Table 1. A list of the MM5 model physics and parameterizations used in the numerical experiments. All physics and parameterizations are applied at the three nested model domains, except that the cumulus parameterization is deactivated in the inner (third) domain.

\begin{tabular}{ll}
\hline Physics/Parameterization & MM5 \\
\hline Cloud microphysics scheme & Goddard SFC graupel scheme \\
Longwave radiation scheme & RRTM scheme \\
Shortwave radiation scheme & Goddard shortwave scheme \\
Boundary layer parameterization & MRF scheme \\
Cumulus parameterization & Kain-Fritsch scheme \\
Surface-layer scheme & Monin-Obukhov similarity scheme \\
Land-surface parameterization & Unified Noah land-surface model \\
\hline
\end{tabular}

Table 2. Numerical experiments in this study.

\begin{tabular}{ll}
\hline Experiments & Descriptions \\
\hline M & The control run (without a bogus vortex) with the lowest level specified at $\sigma=0.993$ (about $160 \mathrm{~m})$. \\
MV & $\begin{array}{l}\text { As in the control run, but a bogus vortex with maximum wind speed }\left(38 \mathrm{~m} \mathrm{~s}^{-1}\right) \text { and the radius of the wind speed at } 34 \mathrm{knots}(300 \mathrm{~km}) \\
\text { for Morakot are assimilated by } 4 \mathrm{DVAR} \text {. The bogus vortex is a specified Rankine vortex used to replace the vortex of the background } \\
\text { analysis. } \\
\text { As in MV but with the lowest level specified at } \sigma=0.998 \text { (about } 50 \mathrm{~m}) .\end{array}$ \\
MV_noTW & As in MV but with removal of Taiwan topography. The terrain heights of Taiwan island are simply reset to zero. \\
MV_noGN & As in MV except that the initial Goni storm has been suppressed by BDA with an additional weak bogus vortex for Goni. \\
& As in MV except that the initial Morakot typhoon has been suppressed by BDA with a weak bogus vortex for Morakot.
\end{tabular}




\section{SYNOPTICS AND OBSERVED RAINFALL IN TAIWAN}

\subsection{The Synoptic Conditions}

Typhoon Morakot formed northeast of the Philippines at 1800 UTC on 3 August 2009. It then moved to the east of
Taiwan and developed into a moderate typhoon near $131^{\circ} \mathrm{E}$ at 1230 UTC 5 August 2009. Morakot headed westward steadily at a speed of about $22 \mathrm{~km}$ per hour until its center was close to east Taiwan (see the best track of CWB in Fig. 1b). Near and after landfall, Morakot slowed significantly to about $10 \mathrm{~km}$ per hour (less than $3 \mathrm{~m} \mathrm{~s}^{-1}$ ). The syn-
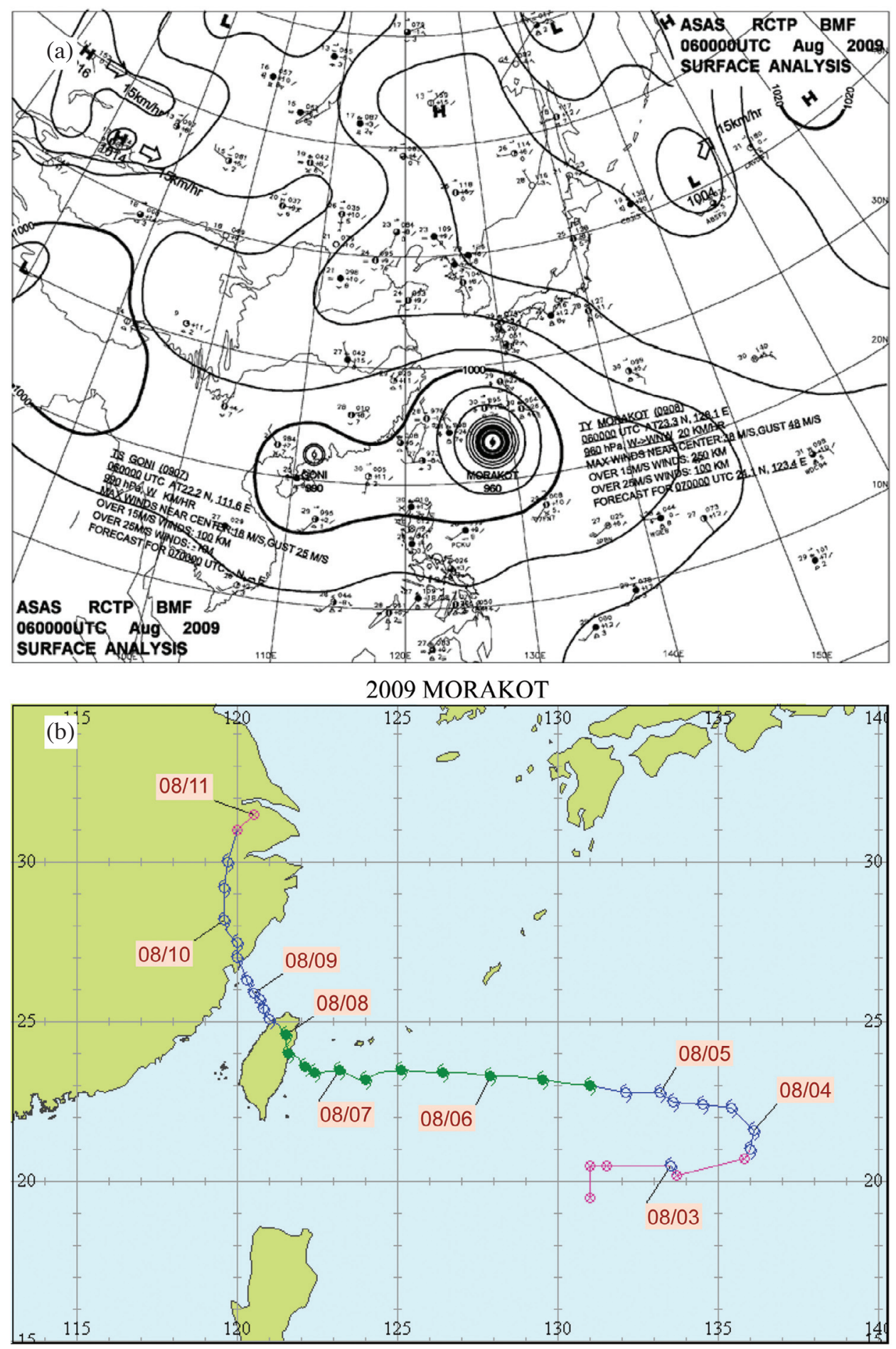

Fig. 1. (a) The surface weather analysis at 0000 UTC 6 August 2009 by CWB, and (b) the best track during the life time of Morakot indicated by the solid (open) typhoon symbol for the stage of typhoon (tropical storm) (courtesy of CWB). 
optic weather analyses on the surface at 0000 UTC 6 August 2009 identified Morakot's center about 660 km east of Taiwan with a maximum wind of $38 \mathrm{~m} \mathrm{~s}^{-1}$ and a central pressure of $960 \mathrm{hPa}$ as shown in Fig. 1. Meanwhile, the weaker Tropical Storm Goni developed west of Hong Kong with a maximum surface wind speed of $18 \mathrm{~m} \mathrm{~s}^{-1}$ and a central pressure of $990 \mathrm{hPa}$. The coexistence of both Morakot and Goni is also indicated by satellite imageries at 1830 UTC 5 and 0030 UTC 6 August 2009 (figures not shown). Both the cyclonic systems can still be detected above $500 \mathrm{hPa}$ by the global analyses as shown in Fig. 2. As will be discussed later, the Goni vortex plays an auxiliary role in enhancing the rainfall in south Taiwan at later times when Morakot passed over Taiwan. For synoptic conditions, the East Asian summer monsoon prevailed from South Asia to the western North Pacific, as usually shown during the revival stage of July $16^{\text {th }}$ to September $30^{\text {th }}$ (e.g., Matsumoto 1989 ; Wang and Chen 2008). The southwesterly to westerly flow of the East Asian summer monsoon was rather intense at lower levels during Morakot (Hong et al. 2010; Chien and Kuo 2011).

As Morakot was steered by the environmental easterly wind at the southwest flank of the subtropical Pacific high, its major circulation was embedded into the eastern fetch of the monsoon trough. At this time, Taiwan was actually situated at the northern periphery of the prevailing wind, which was near the saddle point between the southerly wind of the Goni Storm and the northerly wind of Typhoon Morakot (Fig. 2a). Such a monsoon trough is normally observed in
South Asia during summer, but for this period the monsoon appeared to be very active and persisted for a long time, coincidentally with one developing tropical storm near Taiwan and one developing typhoon approaching Taiwan.

\subsection{Rainfall in Taiwan}

Figure 3 shows the daily observed rainfall and the total accumulated rainfall for the three days (0000 UTC 6 August 2009 - 0000 UTC 9 August 2009). Overall, Morakot brought a maximum total rainfall of about $3000 \mathrm{~mm}$ over the southwest slope of the central CMR. The observed rainfall during the first day (0000 UTC 6 August - 0000 UTC 7 August) fell in the highlands of the CMR with a maximum of $496 \mathrm{~mm}$ just west of the second highest peak in the northern CMR. At this time, the outer cyclonic flow of Morakot was passing over the CMR and producing intense rainfall on the windward slope. On the second day (0000 UTC 7 August - 0000 UTC 8 August), Morakot moved slower when closer to the island (see Fig. 1) and made landfall in east Taiwan on 1550 UTC 7 August and then covered the whole island for over $15 \mathrm{~h}$ due to its much slower movement near and after landfall. During the second day, most rainfall occurred near the landfall position and south Taiwan experienced the largest amount of $1108 \mathrm{~mm}$ in the vicinity of the southern peak of the CMR. As Morakot slowly moved away from the CMR on the third day (0000 UTC 8 August - 0000 UTC 9 August), intense rainfall was produced near the same location but amazingly increased to a maximum of $1560 \mathrm{~mm}$ slightly
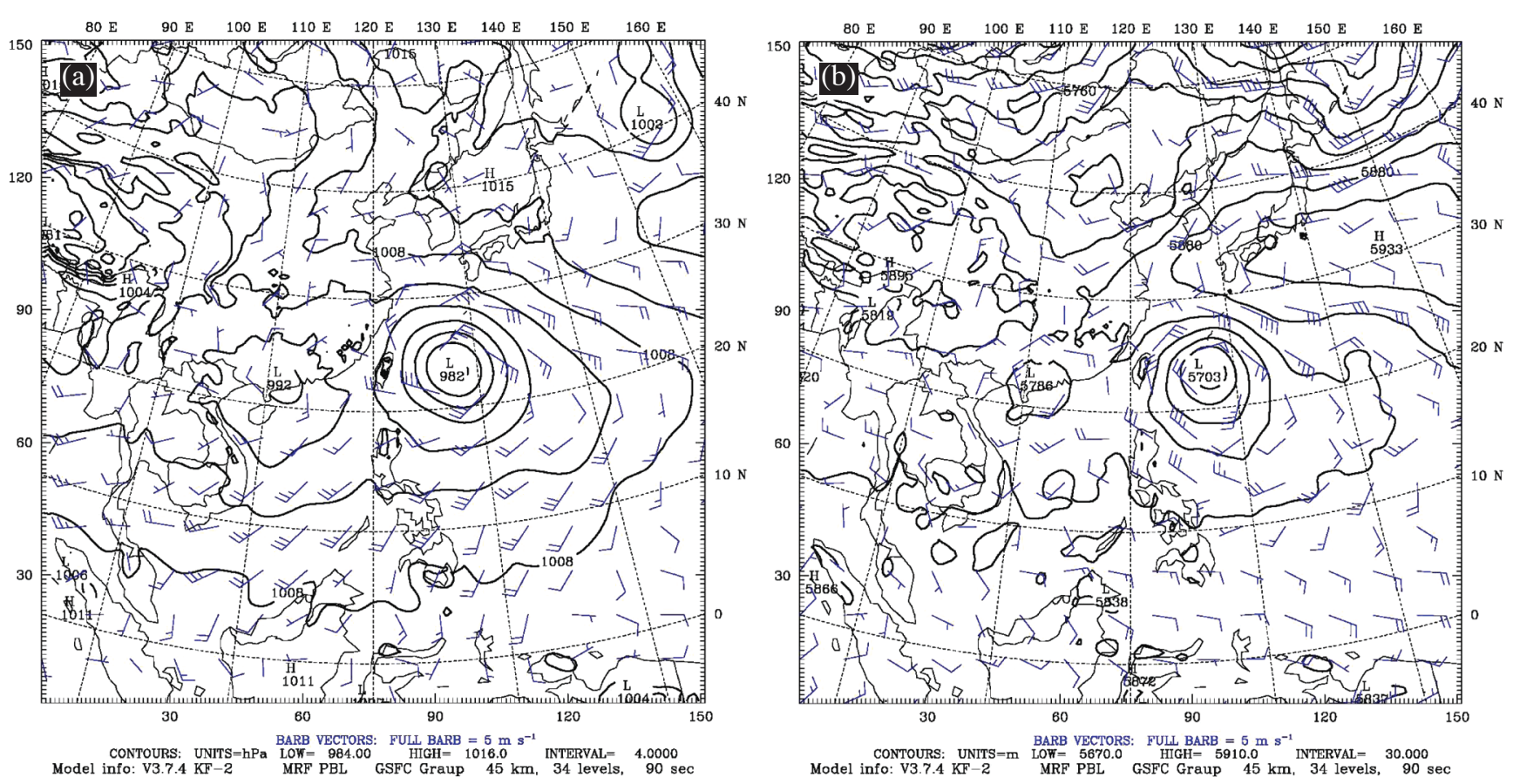

Fig. 2. (a) The sea-level pressure (hPa) and near-surface wind $\left(\mathrm{m} \mathrm{s}^{-1}\right)$ at the initial time (0000 UTC 6 August 2009) for the control experiment $\mathrm{M}$ (without BDA), and (b) as in (a) but for geopotential height (m) and horizontal wind ( $\mathrm{m} \mathrm{s}^{-1}$ ) at the level of $500 \mathrm{hPa}$. 
(a) $8 / 6$ 0000UTC - 8/7 0000UTC

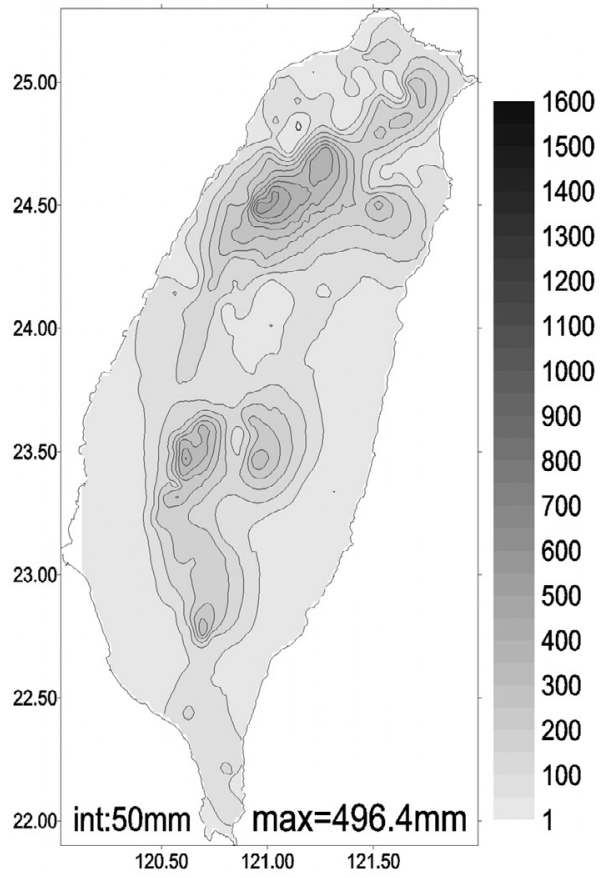

(c) $8 / 8$ 0000UTC - $8 / 90000$ UTC

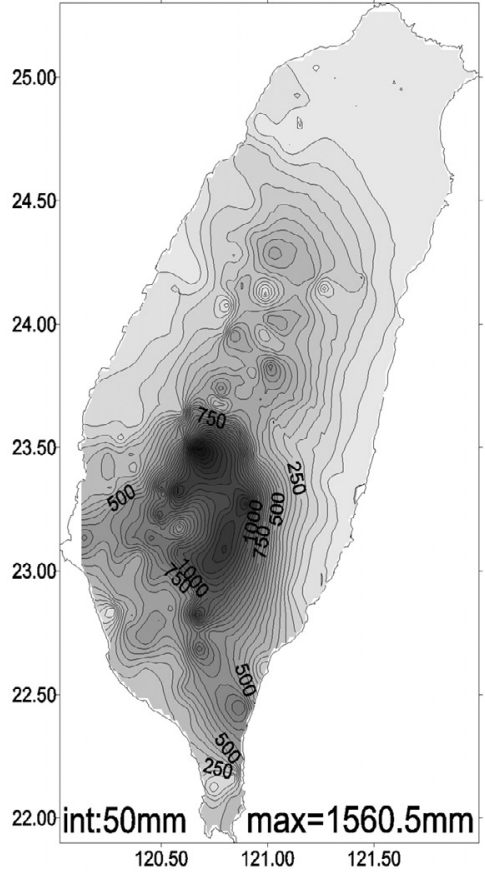

(b) $8 / 7$ 0000UTC - $8 / 8$ 0000UTC

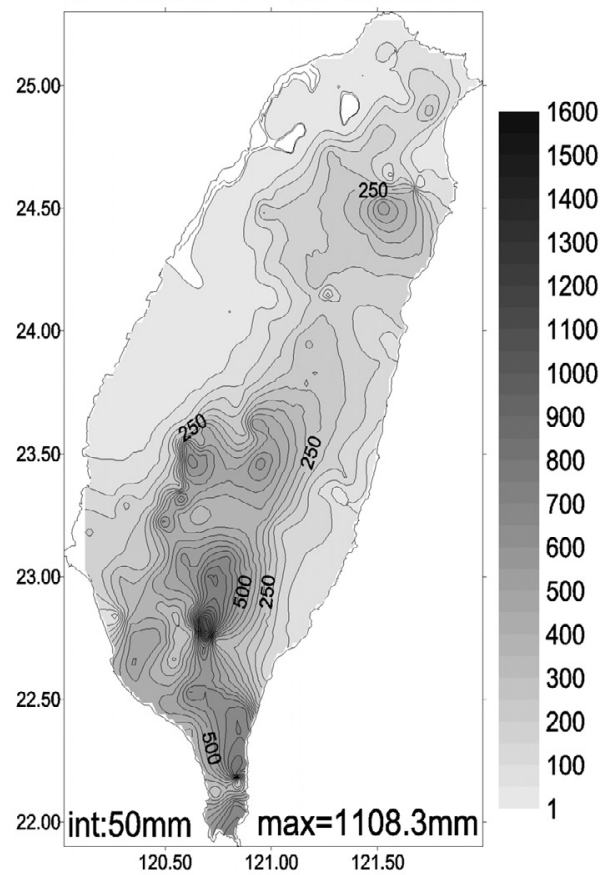

(d) $8 / 6$ 0000UTC - $8 / 9$ 0000UTC

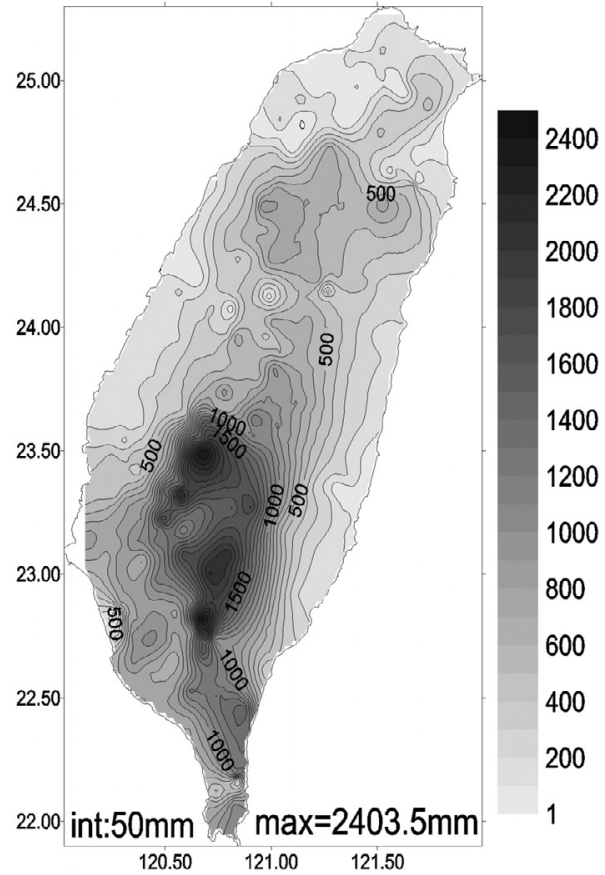

Fig. 3. The observed rainfall (mm) of Morakot in August 2009 during (a) the first day (0000 UTC 6 - 0000 UTC 7), (b) the second day (0000 UTC 7 - 0000 UTC 8), (c) the third day (0000 UTC 8 - 0000 UTC 9), and (d) the three days (0000 UTC 6 - 0000 UTC 9) of the prediction period.

north and southwest of the highest peak of the CMR (around $\left.23.5^{\circ} \mathrm{N}\right)$. The tremendous rainfall primarily resulted from the convergence of Morakot's cyclonic flow and the southwesterly flow near southwest Taiwan, as will be discussed later. Consequently, the major rainfall during the three days was centered in south Taiwan, with a maximum of $2403 \mathrm{~mm}$ just west-southwest of the highest peak of the CMR. The rain continued to fall nearby, but contributed only a total of $500 \mathrm{~mm}$ or so on the fourth day (figures not shown).

\section{THE MODEL RESULTS}

Before presenting the model predictions, the efficacy of the BDA in producing a more consolidated vortex should 
be examined. The model initial conditions were based on the NCEP global analyses at 0000 UTC 6 August 2009 . Without BDA, the initial model minimum sea-level central pressure of Morakot (Fig. 2) was only $982 \mathrm{hPa}$, which is considerably weaker than the observed intensity $(960 \mathrm{hPa})$ as seen in Fig. 1. At lower levels, the southwest monsoon flow west of $120^{\circ} \mathrm{E}$ is intense and larger than $10 \mathrm{~m} \mathrm{~s}^{-1}$. The Goni vortex (near $120^{\circ} \mathrm{E}$ and $20^{\circ} \mathrm{N}$ ) is still detectable at $500 \mathrm{hPa}$, but with much weaker monsoon flow to the south.

Morakot's initial circulation after BDA has been greatly intensified for Experiment MV and is much closer to the observation. Figure 4 shows the forecast sea-level pressure and near-surface wind at 0900 UTC 6 August 2009 (9 h after model integration). At this time, the MM5 provides a consolidated Morakot with a reasonable central pressure of $969 \mathrm{hPa}$ as compared to the observations. Morakot's intensity, after model dynamic adjustment, is somewhat weaker than the observed in terms of central pressure, while their maximum wind speeds are comparable. The intensity forecast for Morakot will be evaluated shortly. In addition, the Goni storm also acquired some intensity with a central pressure of $987 \mathrm{hPa}$. Prior to landfall, intensities of both Storm Goni and Typhoon Morakot do not vary appreciably with time. With these featured structures of Morakot and Goni, the model results of Experiment MV and its related sen- sitivity experiments will be used to investigate the rainfall mechanisms for this event later on.

\subsection{Track and Intensity Predictions}

Time evolutions of typhoon track errors and intensities for the control experiment $\mathrm{M}$ (without BDA) and the experiment MV (as the control experiment M but with BDA) are shown in Fig. 5. The predicted track of MV without Taiwan's topography (i.e., Experiment MV_noTW) is also included for comparison. For MV, the track errors are $177 \mathrm{~km}$ at $24 \mathrm{~h}, 2 \mathrm{~km}$ at $48 \mathrm{~h}$, and $88 \mathrm{~km}$ at $72 \mathrm{~h}$. Although the track prediction is reasonable (with an average error of about $90 \mathrm{~km}$ ) for MV, Morakot appears to deviate somewhat northward at slower translation speeds at earlier times as compared to the best track. These larger track errors at earlier times might be due to the model's dynamic response to the initial bogus vortex. But, Morakot then makes more definite landfall and possesses a more accurate northwestward track after landfall. The slowdown of Morakot after landfall is also well captured by MM5.

For an intensity forecast, the BDA experiment is expected to outperform the no-BDA experiment as shown in Fig. 6. In general, Experiment M (without BDA) keeps a weaker Morakot in congruence with its weaker initial

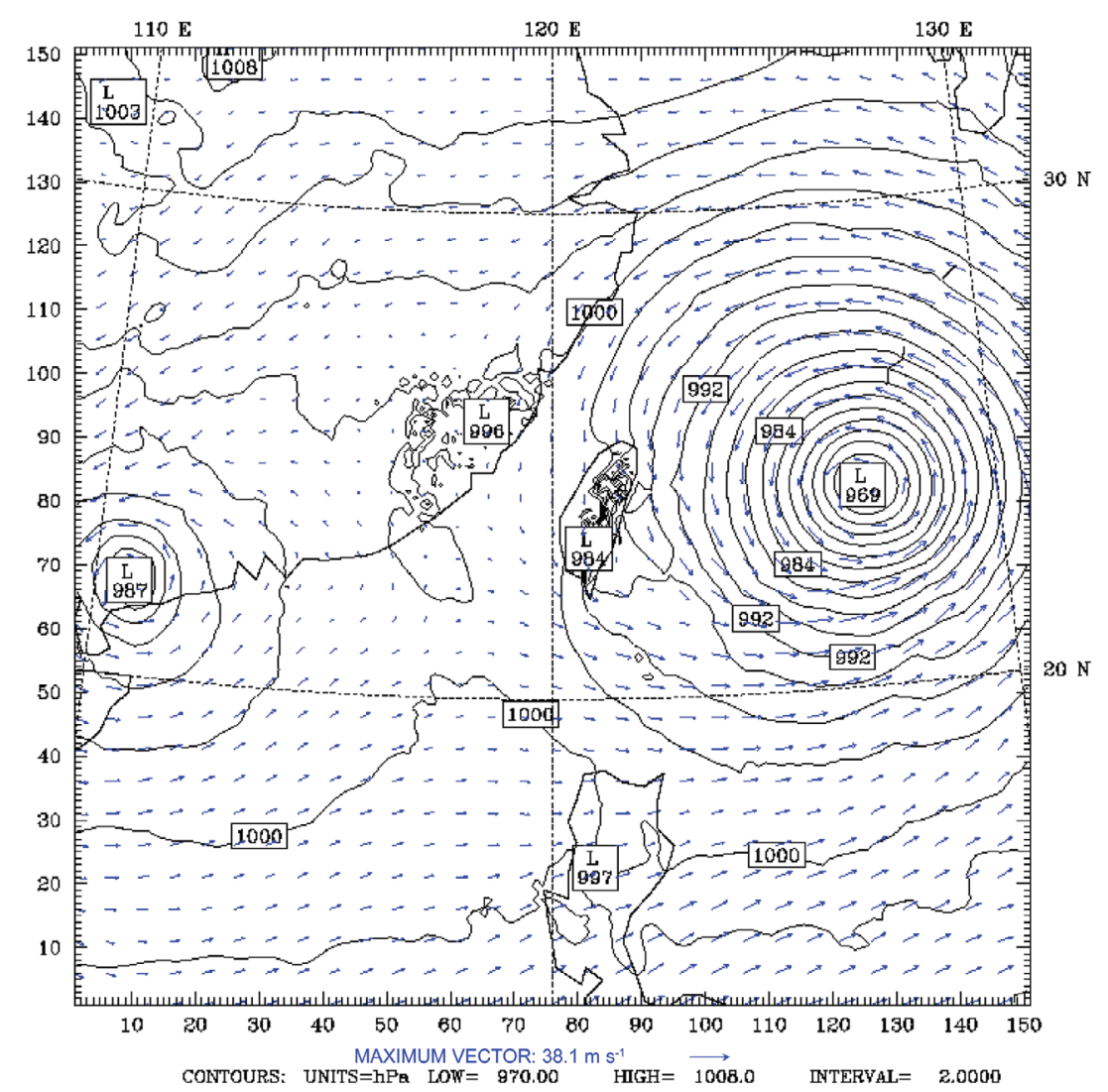

Fig. 4. The sea-level pressure (hPa) and near-surface wind ( $\left.\mathrm{m} \mathrm{s}^{-1}\right)$ at 0900 UTC 6 August 2009 for the control experiment (MV) (with BDA). 


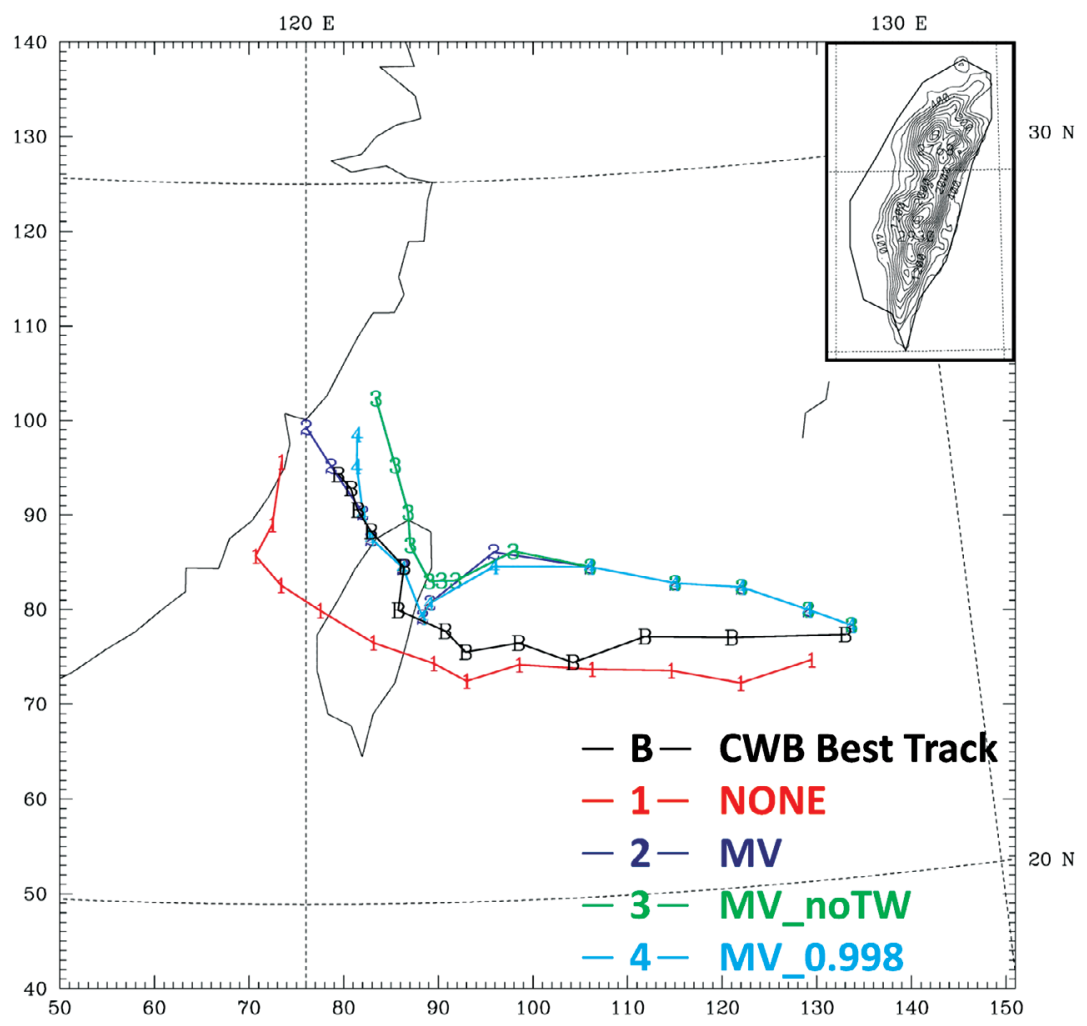

Fig. 5. The predicted tracks for Experiments M (NONE), MV, MV_noTW, MV_0.998 and the CWB best track at an interval of $6 \mathrm{~h}$ (denoted by 1,2 , 3,4 and B, respectively) starting from 0000 UTC 6 August 2009. Taiwan topography at a contour interval of 200 m used in the finest model domain is also overlapped at the northeastern corner.
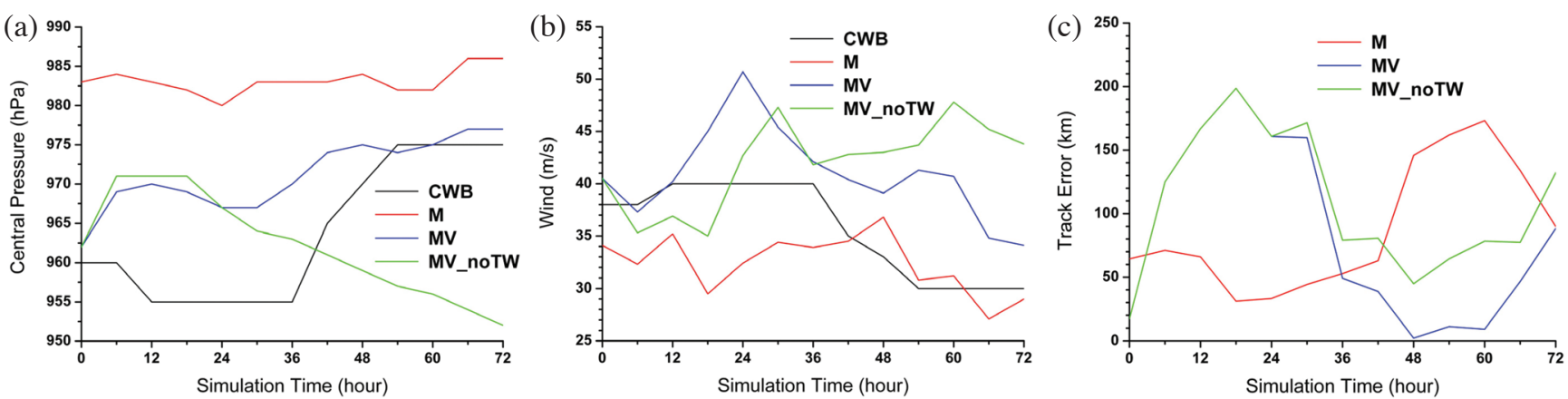

Fig. 6. (a) The 72-h evolution of the predicted sea-surface central pressure starting from 0000 UTC 6 August 2009 for Experiments M, MV, MV_ noTW and the CWB observations at an interval of $6 \mathrm{~h}$ (denoted by red, blue, green, and black, respectively), (b) as in (a) but for surface maximum wind speed, and (c) as in (a) but for track errors of Morakot.

intensity, except that a gradual weakening is found at later times after Morakot makes landfall. The Morakot intensity of MV_noTW (without Taiwan topography) indeed is stronger than MV after $24 \mathrm{~h}$ (when Morakot is nearing landfall), and is much stronger than the observed after $36 \mathrm{~h}$. This clearly indicates the efficacy of the high mountain on diminishing the typhoon intensity in MV. As a result, $\mathrm{MV}_{-}$ noTW gives larger track errors by the end of the prediction (Fig. 6c).

Based on ensemble forecasts with regard to the sensi- tivity of initial synoptic perturbations (but not varying the vortex intensity), Fang et al. (2011) demonstrated the predictability of Morakot's track and the extreme rainfall among 32 member experiments. Varying the size and intensity of the initial typhoon vortex, however, may affect the track as well, as found in modeling studies (e.g., Lin et al. 2005; Wu et al. 2009). We have also conducted more vortex sensitivity tests by varying vortex profiles, but found no improvement in track prediction. This probably indicates a limit to the predictability of Morakot's track when only variations of 
the initial vortex profile are considered. Predictability of accumulated rainfall in Taiwan, however, is still promising as the predicted track of Morakot is not deviated appreciably as to manipulate the rainfall distribution. This will be elucidated in more detail in the next subsection.
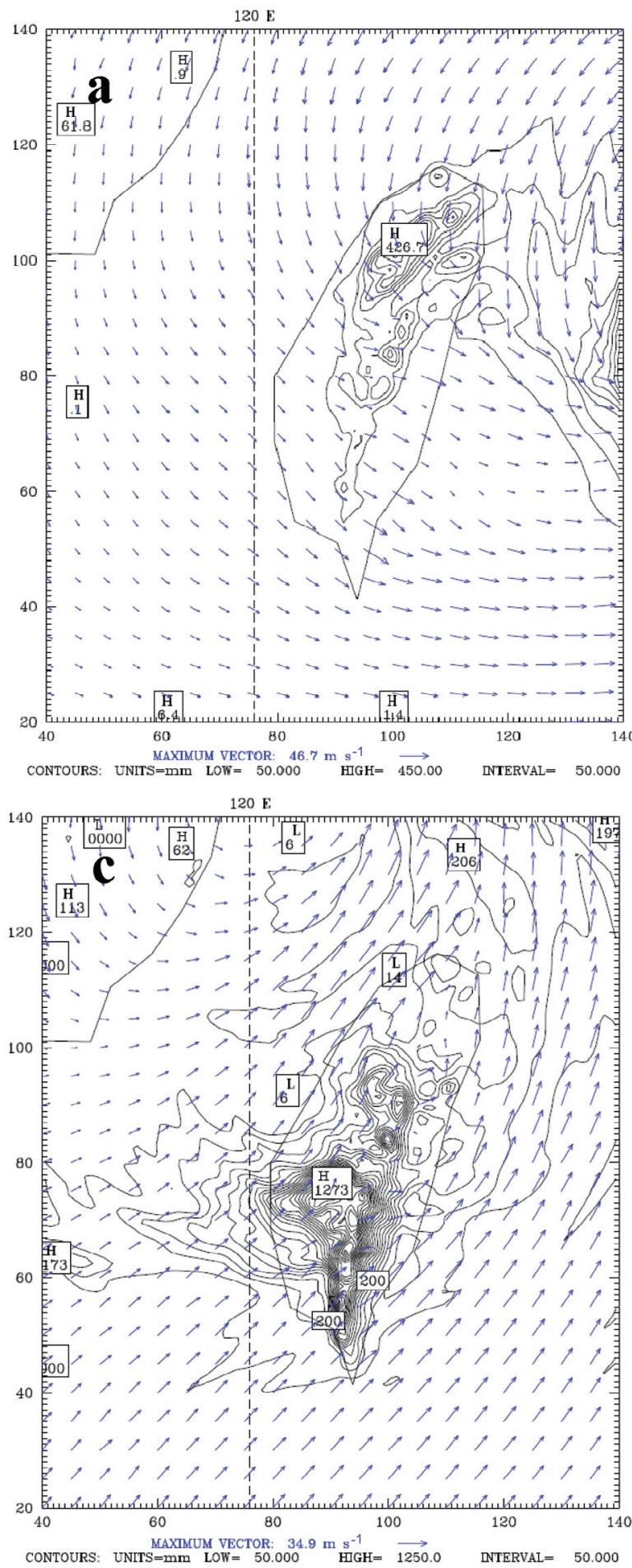

\subsection{Rainfall Prediction}

Figure 7 shows the predicted rainfall and near-surface wind for the MV experiment. Note that the model results from the sensitivity test MV_0.998 (with the lowest model
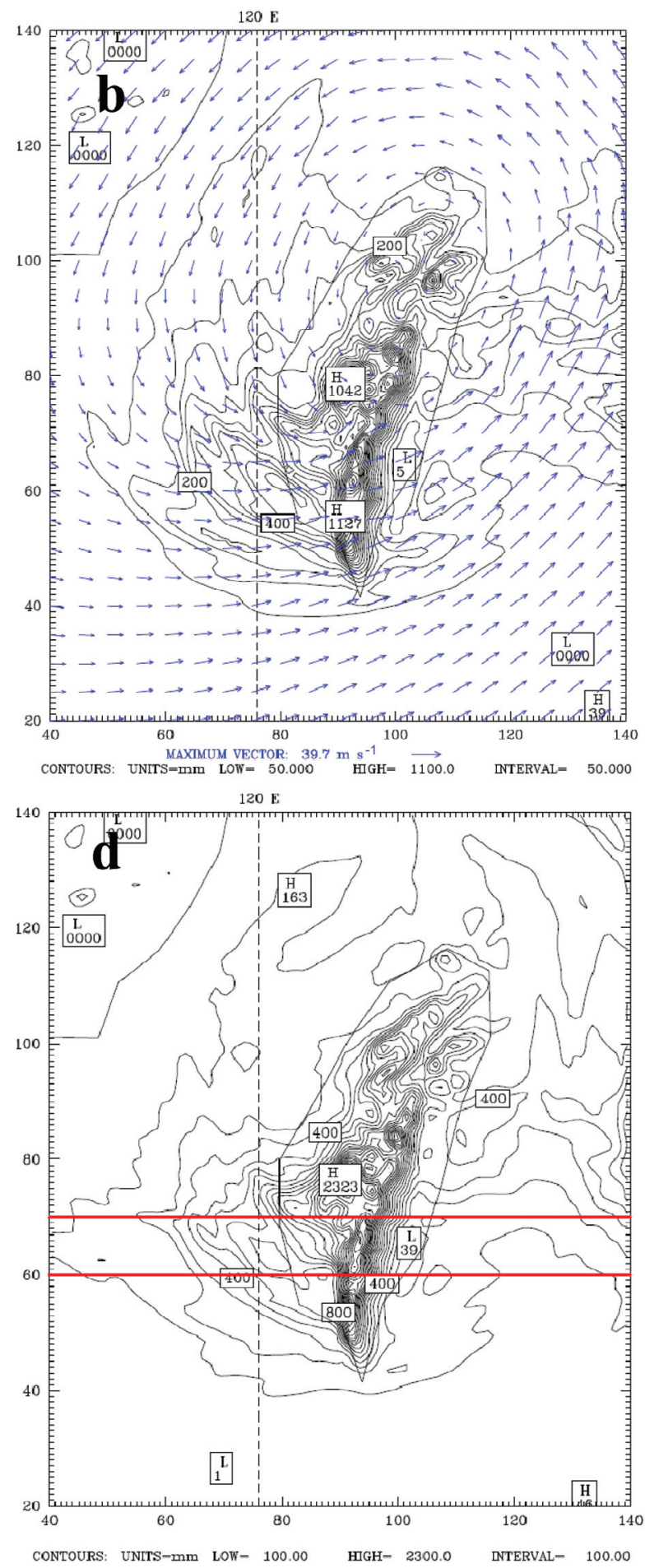

Fig. 7. The accumulated rainfall (mm) during (a) the first day, (b) the second day, (c) the third day, and (d) the total three days for the forecast of the control experiment (MV). The near-surface winds $\left(\mathrm{m} \mathrm{s}^{-1}\right)$ at 24, 48, and $72 \mathrm{~h}$, are also overlapped in (a), (b) and (c), respectively. Contour intervals are $50 \mathrm{~mm}$ for daily rainfall and $100 \mathrm{~mm}$ for total rainfall. In (d), the two red lines indicate the two cross sections shown in Fig. 10. 
level of about $50 \mathrm{~m}$ ) are essentially similar to MV. The northward deviated track on the first day, as mentioned above, caused the MM5 to underestimate the large rainfall near the highest peak of the CMR. Most of the major rainfall in Taiwan and especially the maximum rainfall near northeast Taiwan are well predicted when the track is closer to that observed on the second day. The distribution of extreme rainfall near the highest peak is somewhat extended northeastward in the forecast, again due to the deviated track and further northward flow convergence. As the forecasted track becomes more accurate on the third day, the distributions and amounts of major rainfall are quite similar to the observations. The predicted total accumulated rainfall in the three days agrees very well with the observations, with a maximum $(2323 \mathrm{~mm})$ over the windward slope of the highest peak.

The experiment MV in this study using MM5 has shown reasonable rainfall predictions for the westbound Morakot accompanied by extreme rainfall in Taiwan. The occurrence of consistent model rainfall predictions is, of course, not mere coincidence, but rather a consequence of the "terrain-locking" mechanism as mentioned in the introduction. Predictability of the accumulated rainfall associated with typhoons impinging Taiwan at different directions was also shown by Lin et al. (2002), Wu et al. (2002, 2009), Chiao and Lin (2003), Huang et al. (2005) and Yang et al. (2008) using MM5, and by Chien et al. (2008) and Lee et al. (2008) using WRF. These successful rainfall predictions benefited essentially from the presence of the high CMR in Taiwan that provides the orographic uplift of typhoon flow to produce intense rainfall. The essence of the CMR in Morakot's rainfall has also been noted by Fang et al. (2011) based on the WRF ensemble forecasts. In this study, the deterministic forecast from the MM5 with BDA agrees well with the observations (especially the track at later stages) and will be helpful to explain the possible mechanisms of the extreme rainfall in Taiwan in the next section. We have also investigated other factors (e.g., the Goni storm and the monsoon flow) that affect the extreme rainfall as well.

\section{POSSIBLE MECHANISMS RESPONSIBLE FOR EXTREME RAINFALL IN TAIWAN}

\subsection{The Role of the CMR}

To explore the role of the CMR with regard to rainfall production in Taiwan, we have conducted a terrain sensitivity experiment: MV_noTW, with a removal of the Taiwan topography, for the MV experiment. As shown in Fig. 8, distributions of the predicted daily rainfall in general differ greatly from those with inclusion of the CMR. The rainfall maximum on the third day is less than $300 \mathrm{~mm}$ in south Taiwan, which is significantly smaller than that from MV (with the inclusion of Taiwan's topography). Consequently, patterns of total accumulated rainfall (not shown) do not
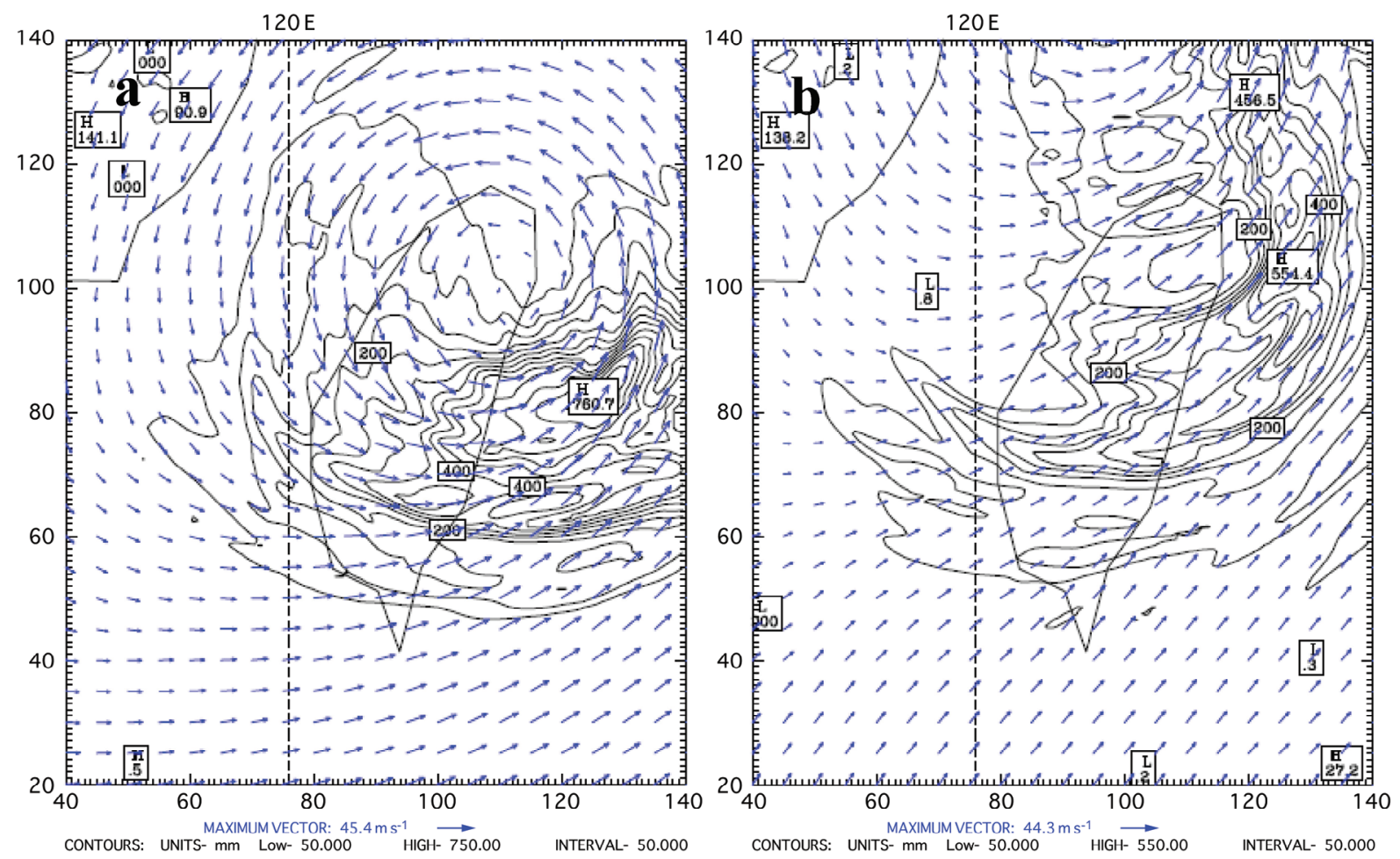

Fig. 8. The accumulated rainfall (mm) for Experiment MV_noTW during (a) the second day, and (b) the third day. Contour intervals are 50 mm. The near-surface winds $\left(\mathrm{m} \mathrm{s}^{-1}\right)$ at $48 \mathrm{~h}$ and $72 \mathrm{~h}$ are also overlapped in (a) and (b), respectively. 
resemble the contours of topographic heights, despite the fact that the associated landfall and track do not deviate appreciably from the observed track. We found that removal of Taiwan's topography has resulted in a significant reduction (more than two thirds) in the 72-h accumulated rainfall maximum. Not surprisingly, a relatively larger amount of accumulated rainfall is still produced in the southern portion of Taiwan, as a manifestation of the efficacy of a local convergence between the cyclonic typhoon flow and southwesterly environmental flow. Similar results are also found in Ge et al. (2010) except for the southwest convection extension. These comparative rainfall patterns may also support the contention that the extension of intense rainfall to the southwest of Taiwan, as seen in Fig. 7d, is not entirely a response to the upstream influence of the orography.

\subsection{The Favorable Synoptic Environments}

A southwesterly flow at lower levels may become blocked by the high CMR rather than pass over since the flow is often associated with a low Froude number defined as $U / N h$ where $U$ is upstream wind speed, $N$ the stability frequency and $h$ the mountain height (Smolarkiewicz and Rotunno 1989). However, the Froude number associated with the flow will become much larger (over unity) for an intense typhoon vortex with the stronger wind speed and significantly reduced $N$ due to the effects of moisture saturation.

For the Morakot case, the environmental synoptic conditions are in fact favorable for convective rainfall as the lower atmospheric flow becomes more moistened or even saturated in the vicinity of Taiwan (Hong et al. 2010; Chien and Kuo 2011). Figure 9 shows the equivalent potential temperature $\left(\theta_{\mathrm{e}}\right)$ and convective available potential energy (CAPE) at the model's lowest level (about 160-m height) above the surface. As expected, both $\theta_{\mathrm{e}}$ and CAPE are much lower over the continent than over the ocean. At 0000 UTC 7 August, most of the oceanic region was already well preconditioned by high $\theta_{\mathrm{e}}$ (above $360 \mathrm{~K}$ ) and CAPE (up to $3000 \mathrm{~J} \mathrm{~kg}^{-1}$ ), except for the southern flank of Morakot which transported colder continental air over the CMR by the cyclonic flow. The vortex core and spiral bands of Morakot as well as the South China Sea are regions of higher CAPE. At 0000 UTC 8 August, there were local maxima of CAPE and $\theta_{e}$, one near the west coast of Taiwan where the Morakot vortex resided and the other near the Goni storm. High CAPE (above $3300 \mathrm{~J} \mathrm{~kg}^{-1}$ ), reaching a regime of extremely convective instability, exists along the southwesterly flow and persists for a long time. Note that the largest CAPE decreases considerably with the starting height of the parcel; for example, at about $1 \mathrm{~km}$, the maximum CAPE of the monsoon belt over the ocean is only about $1000 \mathrm{~J} \mathrm{~kg}^{-1}$. Hence, preconditioning due to low-level moistening of the synoptic environment near Taiwan has facilitated the occurrence of convective instability. Without such precondition- ing, orographic uplifting by itself may not become so robust for rainfall production. This preconditioning appears to be necessary but remains insufficient to account for extreme rainfall in Taiwan. For example, intense rainfall became significantly reduced over the CMR during the fourth day (10 August) when Morakot moved northwestward toward southeast China (figures not shown), but the CAPE southwest of Taiwan remains high.

\subsection{The Locally Enhanced Convection}

As such, the synoptic environment has provided favorable conditions for convective updrafts to develop as the upstream flow is approaching the high CMR. This locally enhanced convection, due to the preconditioning of an incoming flow, should be an important factor for the intense rainfall near and over the CMR. To understand the developed heights of the upstream upslope flow and the associated convective instability, we show in Fig. 10 the predicted equivalent potential temperature and the wind vectors at 0000 UTC 8 August 2009 at the two vertical cross sections cutting through the CMR (see Fig. 7d). No appreciable orographic blocking is found in the front of the CMR in both sections due to that the incoming flow is rather buoyant in terms of convective instability. Convective updrafts have developed up to $10 \mathrm{~km}$ just over the low land west of the CMR (Fig. 10a), which resulted from the latent heating effect of the saturated moisture as transported by the cyclonic typhoon vortex (see Fig. 7b). For the southern section, the upstream westerly inflow, however, develops less with height (Fig. 10b), mainly due to the flow transition between the typhoon and environment. At the downstream side, the convective layer develops only to $7 \mathrm{~km}$ height or so, with much weaker vertical motions. The upward motions upstream of the central CMR are much stronger than those to the south, and in fact first appear about $100 \mathrm{~km}$ upstream of the mountain base. Such intense upward motions at this region are not directly caused by an orographic uplift, but mainly are a result of a strong convergence of the cyclonic typhoon vortex and the environmental flow. This may explain why there is an extension of intense rainfall to the offshore region west of south Taiwan, as seen in Figs. 7b, c.

The cloud convection along the two cross-sections may be dictated by radar reflectivity as shown in Fig. 11 . The cloud convection is stronger and higher over the northern section of the CMR than the southern section. This is because the mountain is higher over the northern section. The strongest upward motions are associated with the largest reflectivity up to $60 \mathrm{dBZ}$ and a top up to $14 \mathrm{~km}$ height. At both cross sections, the severe downslope wind east of the mountain peak advects the clouds downstream but with much less rainfall as seen in Fig. 7b. At the southern section, one zone with moderate reflectivity is present upstream of the major convection, again as a result of the convergence of 
the monsoon flow and the outer typhoon vortex. The rainfall extension to the west of the southern CMR is thus a manifestation of the flow convergence. These convective clouds along the flow convergence are also clearly identified by CWB radar echo maps (figures not shown, available at the
CWB website). As the Morakot vortex moves northward, the flow becomes more straightforward and upslope over the northern section thus producing intense rainfall more effectively. It may explain why the maximum accumulated rainfall is present just southwest of the highest peak.

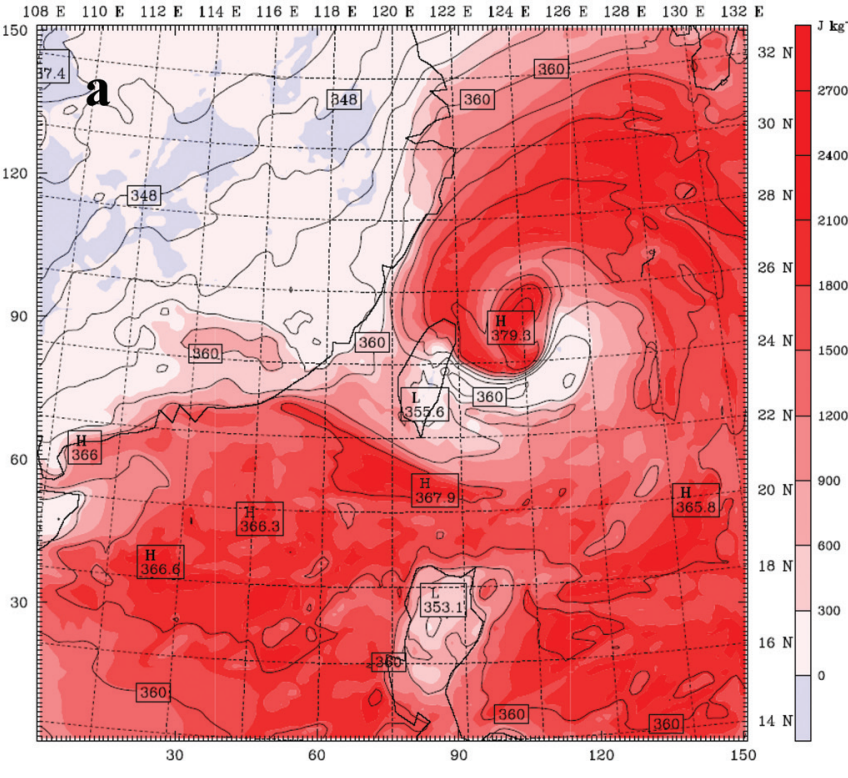

CONTOURS: UNITS $=K$ LOTI $=339.00 \quad$ HIGH $=378.00 \quad$ INTERVAL $=3.0000$

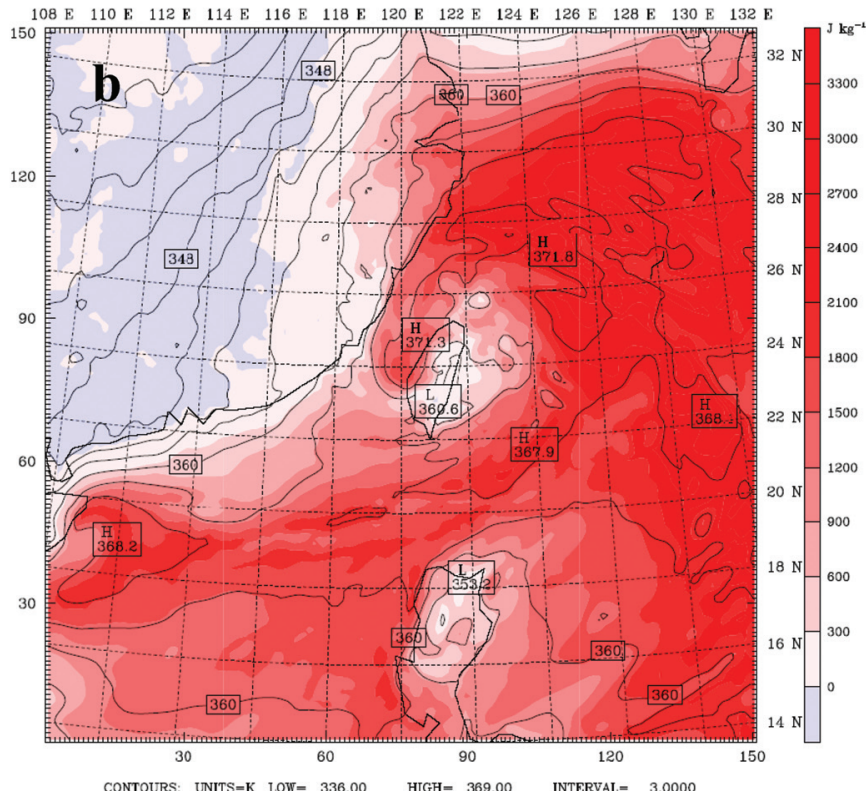

CONTOURS: UNITS $=\mathrm{K}$ LOWF $=336.00 \quad$ HIGH $=369.00 \quad$ INTERVAL $=3.0000$

Fig. 9. (a) Predicted equivalent potential temperature (solid lines at an interval of $3 \mathrm{~K}$ ) and convective available potential energy (CAPE) at units of $\mathrm{J} \mathrm{kg}^{-1}$ (shaped color contours) for Experiment MV at the lowest model level (about $160 \mathrm{~m}$ ) above the surface at $0000 \mathrm{UTC} 7 \mathrm{August} 2009$, and (b) as in (a) but at 0000 UTC 8 August 2009.
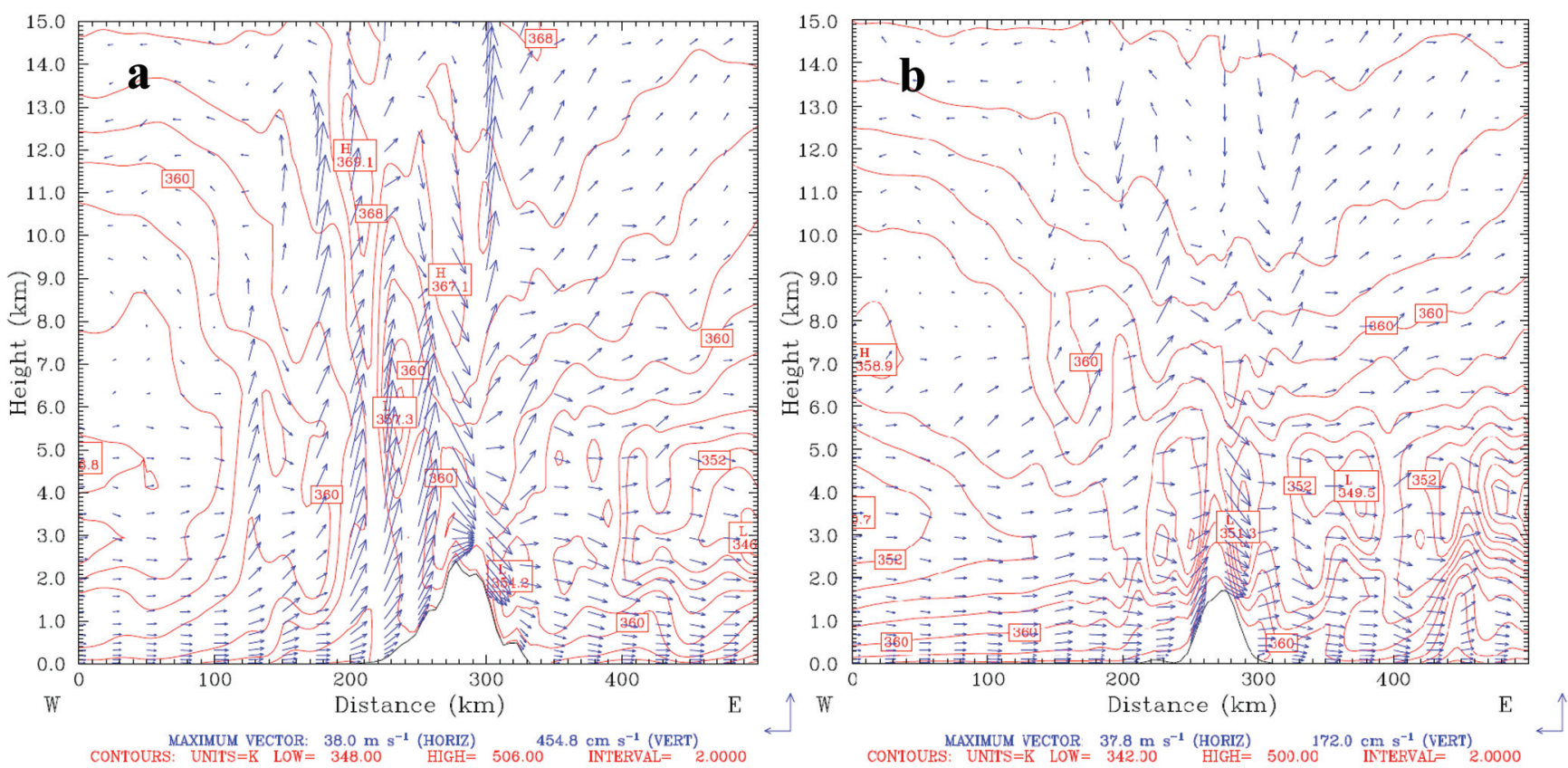

Fig. 10. Predicted equivalent potential temperature (solid lines at interval of $2 \mathrm{~K}$ ) and the wind vectors $(u$ and $w$ ) for Experiment MV at 0000 UTC 8 August 2009 in the vertical cross-section along the line segment at (a) $70^{\text {th }}$ and (b) $60^{\text {th }}$ meridional grids as indicated in Fig. 7d. Magnitudes of maximum $u$ and $w$ are indicated at the right lower corner. 

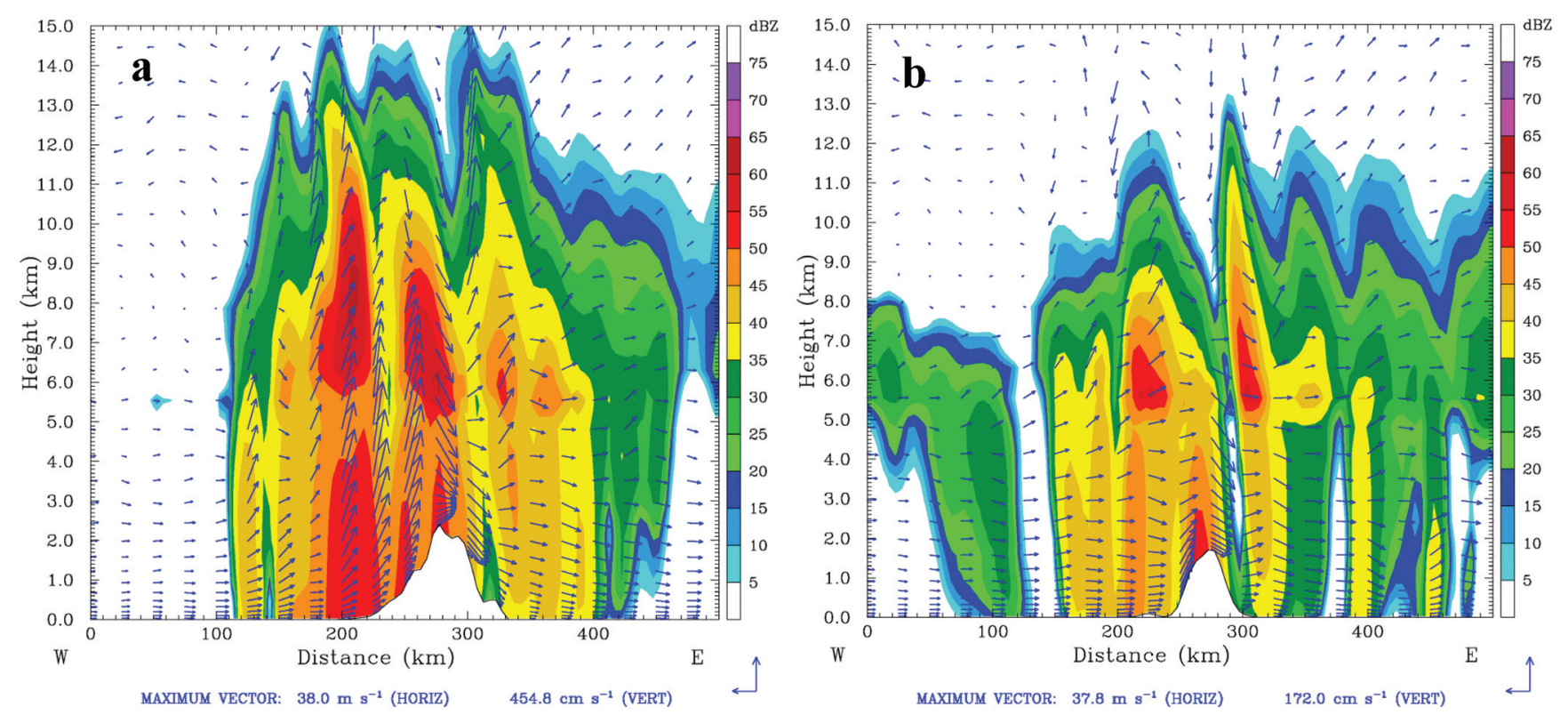

Fig. 11. (a) and (b) as in Figs. 10a and b, respectively, but for radar reflectivity (dBZ).

In order to further identify what flow plays a major role in contributing to the enhanced effects of orographic rainfall, trajectories of particles released along the west slope of the southern CMR are investigated and shown in Fig. 12. Evidently, the twelve particles, released at both model level heights (about $160 \mathrm{~m}$ and $1 \mathrm{~km}$, respectively) at 0000 UTC 8 August 2009, originate from the cyclonic flow of Morakot. At 0000 UTC 9 August 2009, however, the trajectories of the further northern particles near the central CMR emanated from the outer Morakot circulations and the transition flow between the synoptic environment and Morakot typhoon. Near the southern end of the CMR, the parcels have travelled a long distance along the southwesterly belt that brings abundant moisture to facilitate rainfall near Taiwan. This convergent flow (also seen in Fig. 7b) is quite intense in the vicinity of southwest Taiwan and plays an important role in enhancement of local convective rainfall. Figure 12 thus constructs a schematic diagram of the rainfall mechanisms at different stages associated with the westbound Morakot typhoon and the southwesterly summer monsoon, in support of the large-scale analysis by Hong et al. (2010) and Chien and Kuo (2011). Conversely, the convergence may be induced in northeast Taiwan by the northeasterly winter monsoon and the southeasterly flow of the typhoon, which may also result in enhancement of local rainfall, as shown in Wu et al. (2009).

\subsection{The Roles of Goni and Morakot}

To understand why Morakot's rainfall amounts were so intense in the presence of the CMR, we conducted an- other two experiments using the MM5 with the same BDA to adjust the initial vortex intensity. In the first experiment (MV_noGN), a weaker bogus vortex with a sea-level central pressure of $1002 \mathrm{hPa}$ was applied to suppress Storm Goni, but the same bogus vortex in the experiment MV is still used for Morakot. Similarly, in the second experiment (MV_noMK), a much weaker bogus vortex with a sea-level central pressure of $1000 \mathrm{hPa}$ was applied to suppress Typhoon Morakot, while retaining the Goni intensity from the initial NCEP analysis. Consequently, initial Goni storm or Morakot typhoon can be significantly weakened using the BDA through dynamical adjustment. These two experiments were used to explore the potential contributions of Typhoon Morakot and Storm Goni to the total accumulated rainfall in Taiwan.

Figure 13 shows the sea-level pressure and near-surface wind for the Experiment (MV_noGN) and the wind increments (MV minus MV_noGN) at the model initial time. For MV_noGN, there is a cyclonic circulation of the wind increments at the Goni location, while the intense Morakot vortex obtained from BDA remains little affected. We found that deactivation of the initial Goni data did not greatly change Morakot's track and intensity after model integration. In effect, the two approaching cyclone systems may have been affected by each other and such a binary interaction may have led to changes in their motions - the well-known Fujiwhara effect (Fujiwhara 1921). From this sensitivity experiment, however, such effect seems insufficient to influence Morakot's movement, probably due to their large separation distance (Ritchie and Holland 1993).

The sensitivity test with the deactivated Goni shows 

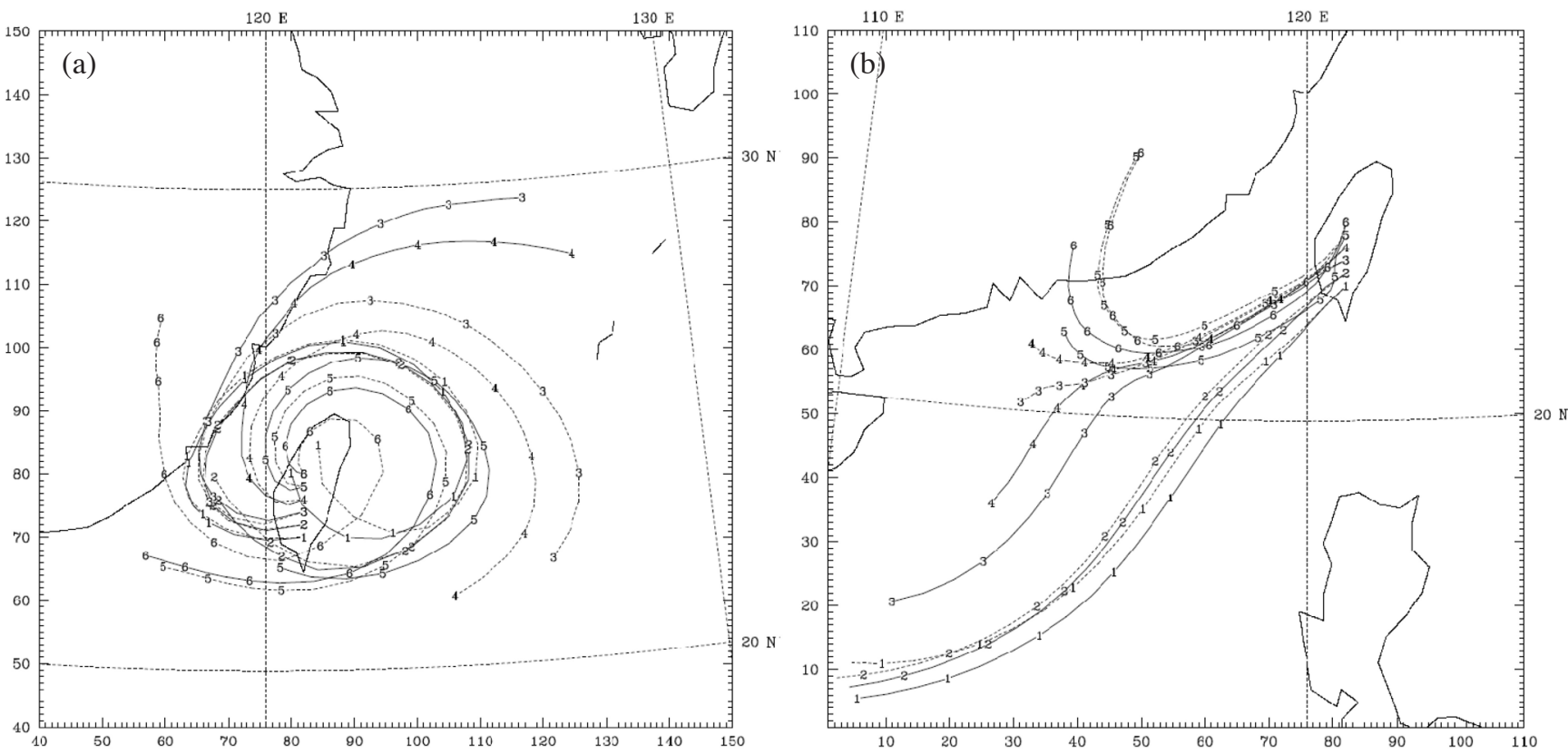

Fig. 12. (a) The model backward trajectories of six particles for the MV Experiment at the lowest model level height (about $160 \mathrm{~m}$ ) above the surface (solid lines) and six particles at the model level height (about $1 \mathrm{~km}$ ) above the surface (dashed lines), all released at 0000 UTC 8 August 2009 , and (b) as in (a) but released at 0000 UTC 9 August 2009.
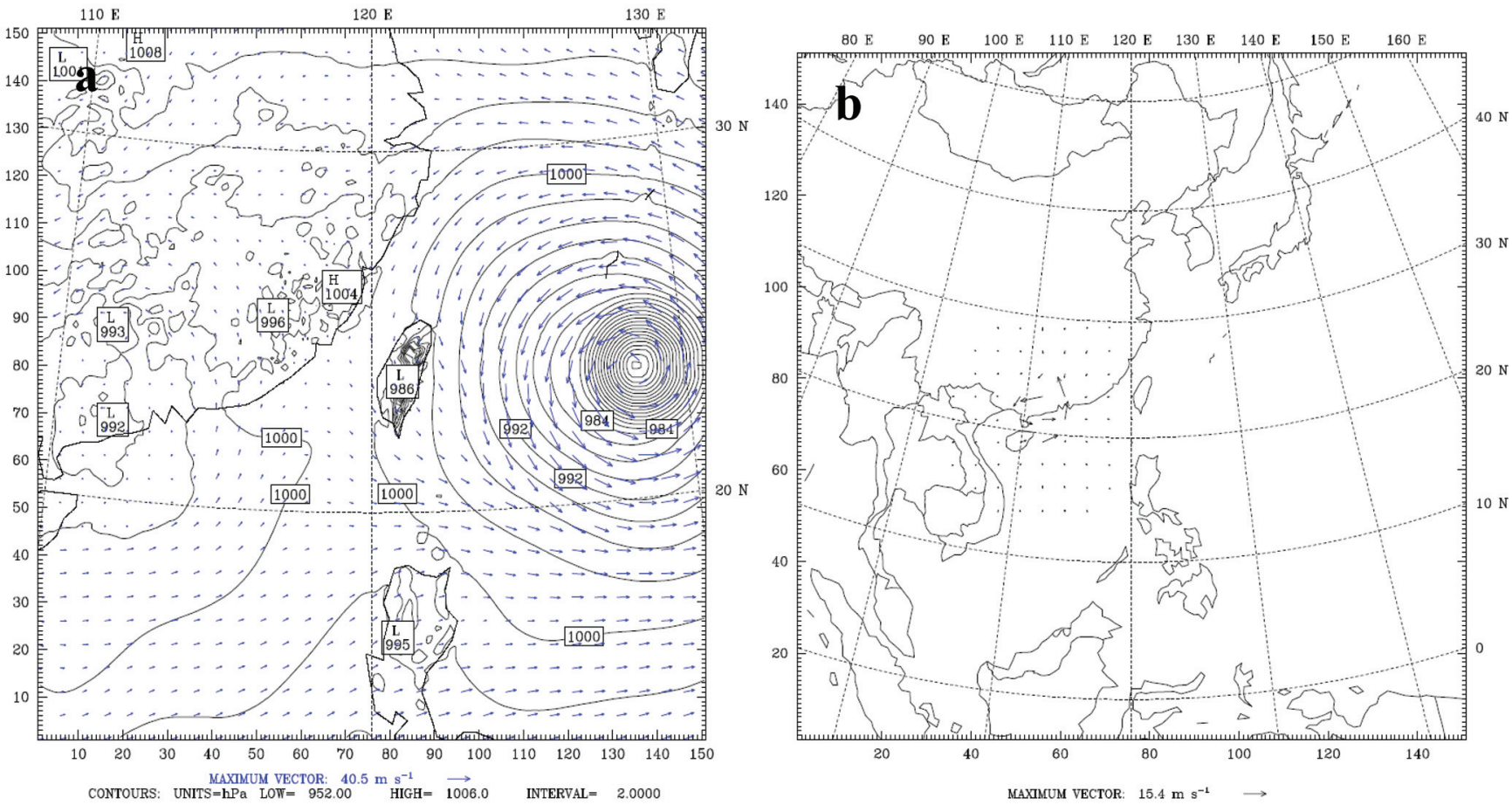

Fig. 13. The model results for Experiment MV_noGN (with the initial deactivated tropical Storm Goni). (a) The initial surface pressure (hPa) and near-surface wind $\left(\mathrm{m} \mathrm{s}^{-1}\right)$, and (b) initial wind increments $\left(\mathrm{m} \mathrm{s}^{-1}\right)$ between MV and MV_noGN.

that the maximum total rainfall near the highest peak of the CMR, as found in Fig. 14, has been significantly reduced to $1737 \mathrm{~mm}$, or about two thirds of the MV experiment. This great reduction is intimately related to the less developed southwesterly flow near south Taiwan (e.g., at 72 h) due to the effect of an initial weaker Goni vortex. In particular, the distributions of the accumulated rainfall during the third day (Fig. 14a) remain similar to those for the MV experiment 

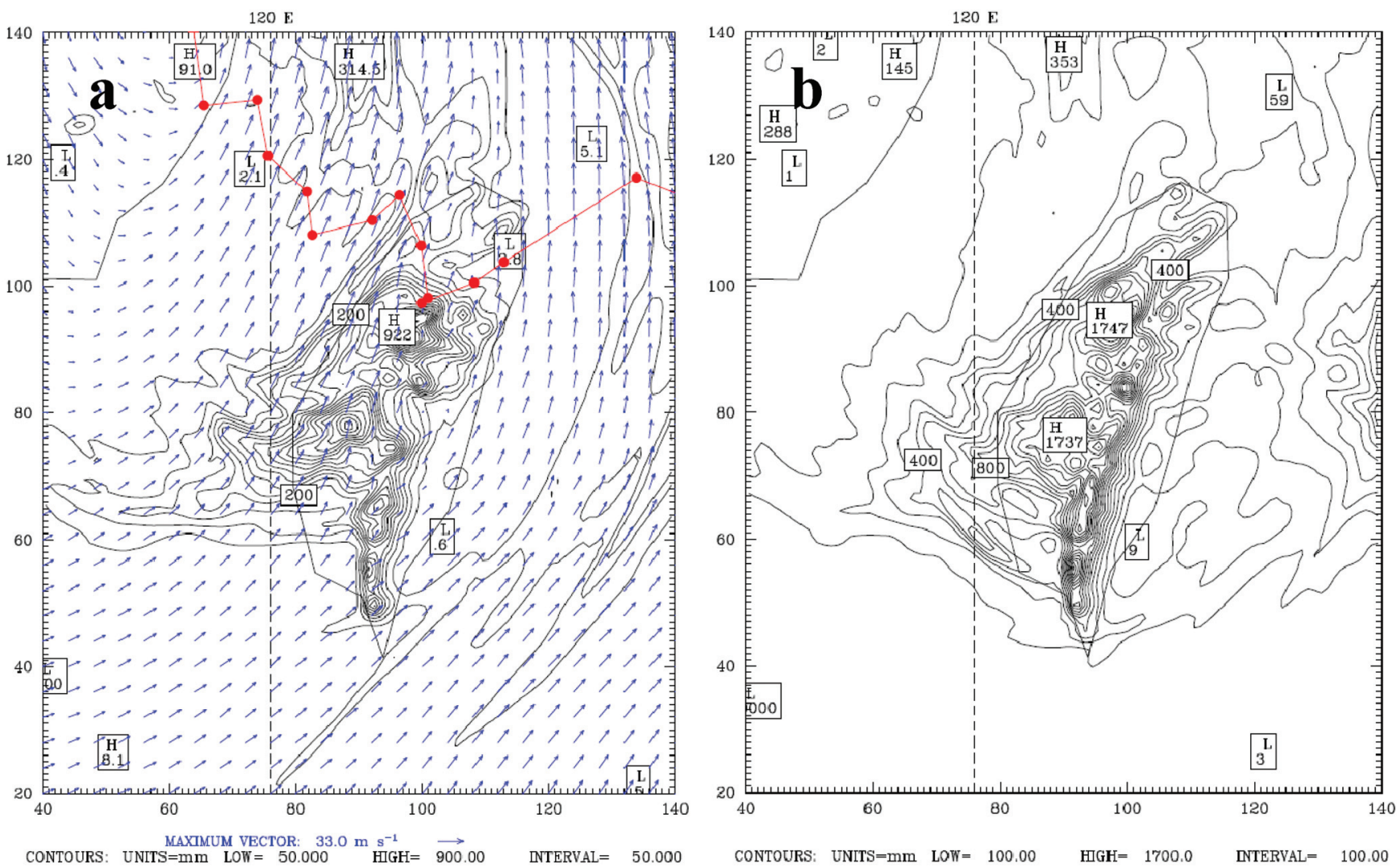

Fig. 14. The accumulated rainfall (mm) for Experiment MV_noGN during (a) the third day, and (b) the total three days. Morakot's predicted track (line with dots) at an interval of $3 \mathrm{~h}$ and the near-surface wind $\left(\mathrm{m} \mathrm{s}^{-1}\right)$ at $72 \mathrm{~h}$ are also overlapped in (a). Contour intervals are $50 \mathrm{~mm}$ for daily rainfall in (a) and $100 \mathrm{~mm}$ for total rainfall in (b).

(Fig. 7c) as Morakot's vortex core has moved to the west side of the island. This indicates that the developing Goni vortex in fact tends to strengthen the environmental flow passing around and over the CMR and thus results in more intense rainfall in south Taiwan. The role of the Goni storm in facilitating the flow convergence with the cyclonic flow of Morakot has also been shown by Chien and Kuo (2011) using global reanalysis data.

Similar to Fig. 12 for the control experiment (MV), Fig. 15 shows the trajectories of the released twelve particles for the experiment with the deactivated Goni (MV noGN). All the trajectories at 48-h emanated from Morakot's circulation, similarly to those for the MV experiment. At $72 \mathrm{~h}$, the trajectories become more concentrated from the northwest of Morakot's center and are different from those from the southwesterly flow in the MV experiment. Since the later particles originate from the colder or dryer places at higher latitudes, the rainfall tends to be reduced over the southern and central CMR.

For the second experiment, MV_noMK (with the initially deactivated Morakot), the predicted typhoon vortex cannot intensify during the first two days as seen in Fig. 16a. The Morakot vortex finally develops into a well-organized typhoon on the third day, but the vortex center has looped east of Taiwan for a long time (see Fig. 16b). With such a vortex core never approaching Taiwan, the island rainfall distributions differ essentially with much smaller amounts (figures not shown). The environmental flows become cyclonic and northeasterly off the southeast China coast and westerly south of Taiwan, which are completely different from the southwesterly prevailing flow for the experiment MV.

\section{CONCLUSIONS}

In August 2009, Typhoon Morakot became the most severe meteorological disaster ever recorded in Taiwan; it originated in the western North Pacific, evolved into moderate intensity, and brought an unexpected total accumulated rainfall of over $2400 \mathrm{~mm}$ in 3 days $\left(6^{\text {th }}\right.$ to the $9^{\text {th }}$ of August 2009 ) in south Taiwan. The CWB official track prediction is reasonably good as compared to most estimates at other operation centers. However, the 72-h accumulated rainfall in south Taiwan as officially issued earlier by CWB was only 600 to $1000 \mathrm{~mm}$, which appears to be significantly underpredicted.

In this study, the regional model MM5 was used to investigate the mechanisms of the induced extreme rainfall 

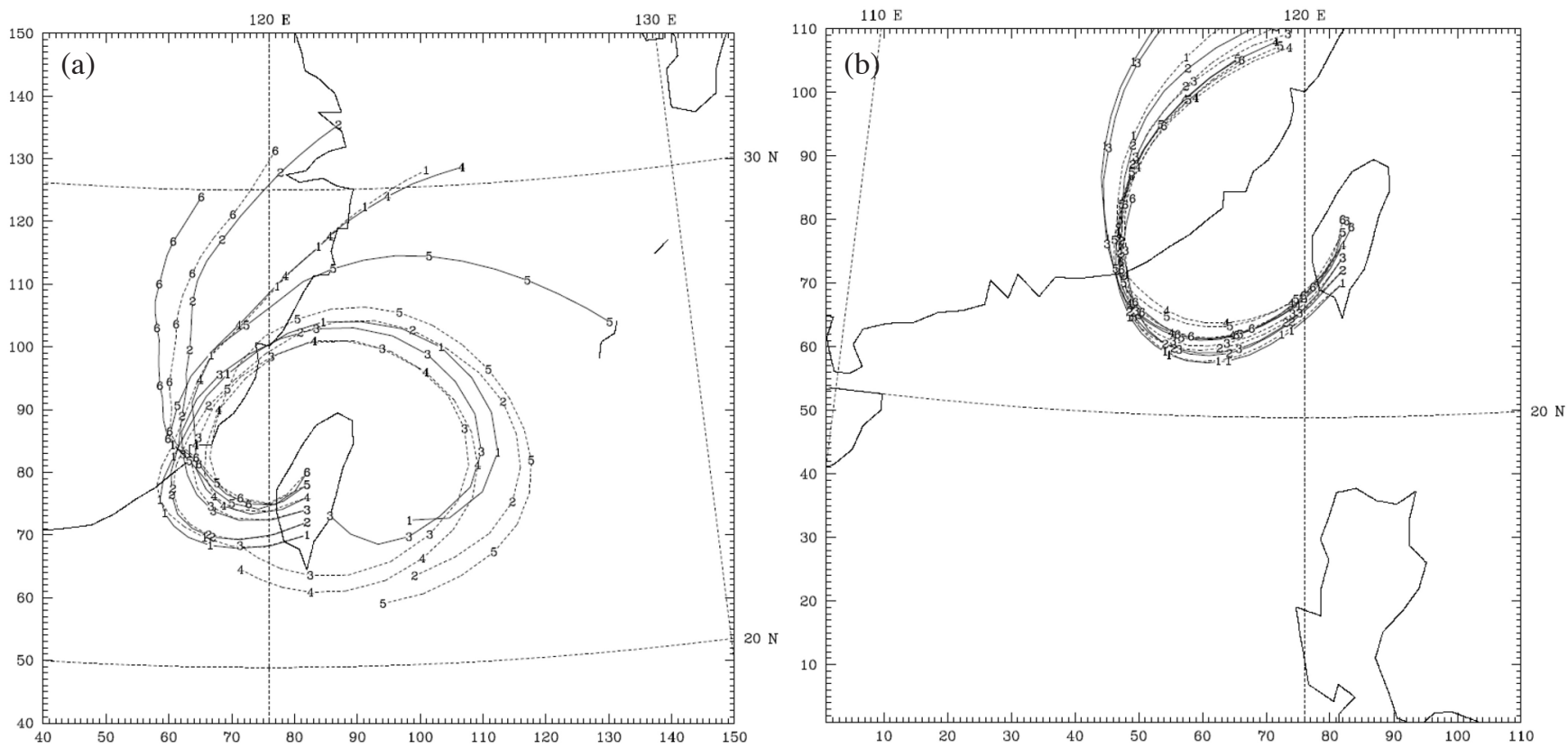

Fig. 15. As in Fig. 12 but for Experiment MV_noGN.
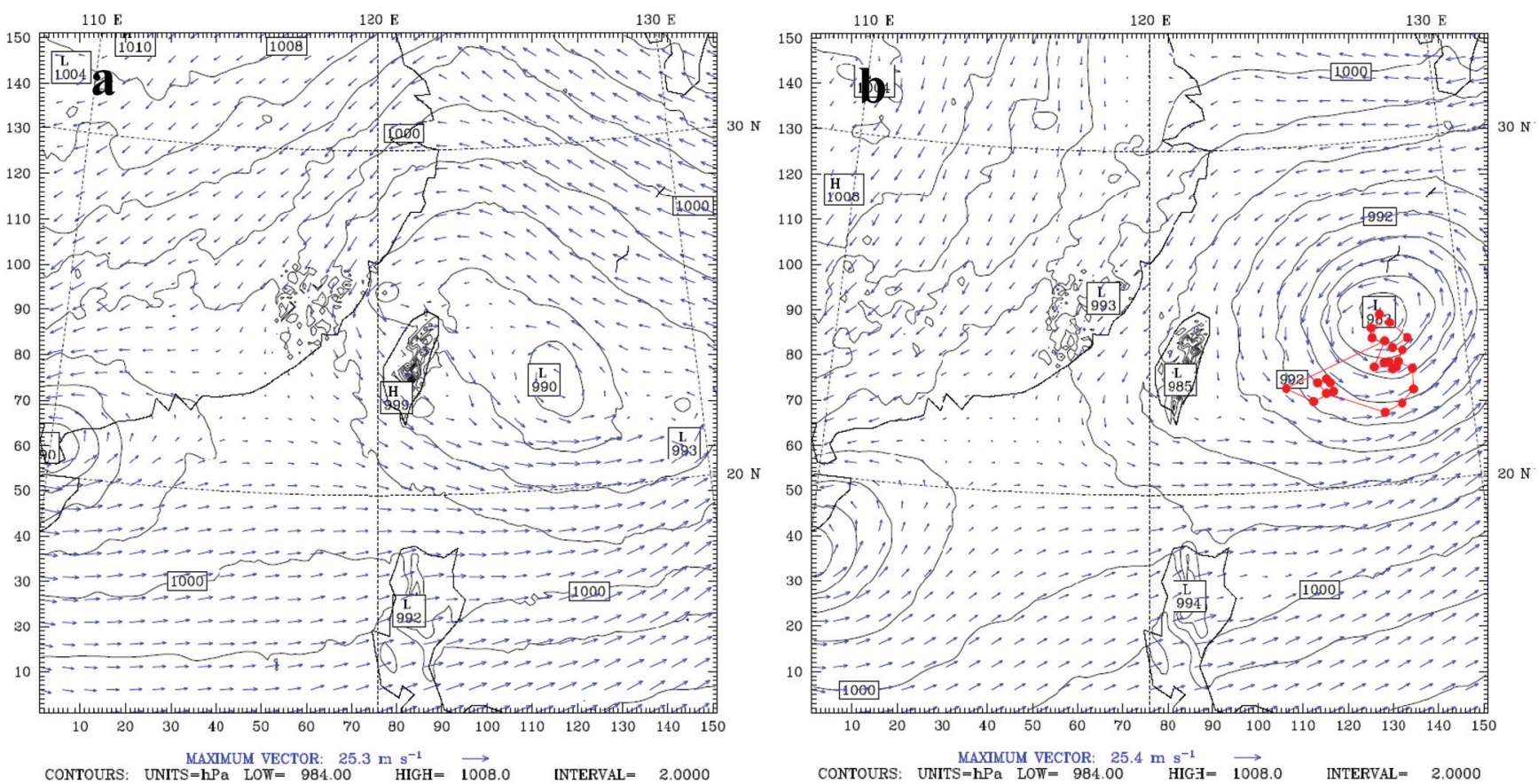

Fig. 16. The sea-level pressure $(\mathrm{hPa})$ and near-surface wind $\left(\mathrm{m} \mathrm{s}^{-1}\right)$ for Experiment MV_noMK (with the initial deactivated Typhoon Morakot), (a) at 0000 UTC 7 August 2009, and (b) at 0000 UTC 9 August 2009. Morakot's predicted track (line with dots) at an interval of 3 h is also overlapped in (b).

in Taiwan for Typhoon Morakot. With predicable extreme rainfall, analyses of the model results may help us to understand the associated mechanisms. The MM5 experiment with bogus data assimilation (BDA) reasonably reproduces the 72-h accumulated rainfall in south Taiwan because of a small track error of only $90 \mathrm{~km}$ on 72 -h average. The BDA helps MM5 to produce a stronger initial vortex and maintain a more consolidated vortex prior to landfall. Major rainfall near northeast Taiwan where landfall was nearby and the maximum rainfall at the southwest slope of the central CMR 
were well predicted by MM5 with a more accurate track at later stages.

When the predicted track was not demonstrably altered from the best track, skillful predictability of accumulated rainfalls in Taiwan has been captured by the model, due to the fact that the high mountain (CMR) in Taiwan plays a major role in effectively intercepting abundant moisture associated with the typhoon circulation as well as the environmental flow; this is confirmed by the terrain sensitivity experiments conducted in this study. The model results show that more than one half of the total accumulated rainfall will be discounted if the Taiwan topography were removed. Also, there no longer exists a close correlation between the geometric distributions of model rainfall and observed rainfall. Similar findings are also presented by Fang et al. (2011) based on ensemble forecasts in regard to initial variations in synoptic analyses (but without changing the Morakot vortex). Therefore, there exists a "terrain-locking" mechanism that might be indicative of amounts and locations of major rainfall on the windward steep slopes. But, why Morakot could bring such huge rainfall amounts to south Taiwan remains an interesting question awaiting further exploration.

As a whole, extreme rainfall in south Taiwan in fact is a consequence of many possible factors. For example, the slowdown of Morakot near and after landfall elongates the period of intense rainfall in Taiwan. In this study, we didn't specifically explore this factor, even though the model did capture its later slowdown. The moving speed of Morakot appears to play an important role in accumulative rainfall production based on an EnKF study (Yen et al.2011). Warm ocean eddies in the vicinity of Morakot's path also are closely involved in the enhancement of local convection embedded in Morakot (Lin et al. 2011). On the other hand, the synoptic environments were also favorable for convective instability to occur; for example, our model results indicate that very large CAPE (up to $3000 \mathrm{~J} \mathrm{~kg}^{-1}$ ) existed over the oceanic region covering the Morakot spiral circulation and the southwesterly monsoon belt that both transported abundant water vapor to south Taiwan which is in agreement with the observational study (Pan et al. 2011). The atmospheric flow in fact exhibited convective instability to a depth of about $10 \mathrm{~km}$ just west of south Taiwan. The convective instability is much larger at low levels associated with most of CAPE. This large-scale low-level preconditioning will be favorable for enhancing intense convective rainfall near Taiwan when the cyclonic typhoon flow becomes convergent with the southwesterly flow to the southwest of Taiwan. Rainfall then can be further intensified by a strong orographic uplift on the steep slopes of the CMR. These results are consistent with the reanalysis study of Chien and Kuo (2011).

To understand the relative importance of possible contributors to the accumulated rainfall in Taiwan, several sensitivity experiments were conducted. Vortex sensitivity experiments were conducted in this study using the BDA to adjust the initial vortex intensity. We found that deactivation of the initial Goni vortex (west of Hong Kong) has resulted in a reduction in a rainfall maximum by about one third, due to the less developed southwesterly flow to the southwest of Taiwan. This has been confirmed by the analysis of the trajectories of several particles released along the west slopes of the southern CMR. There is no southwesterly flow that reaches the CMR slopes when the Goni vortex becomes weak. Most of the major rainfall in Taiwan was produced by Morakot, itself. In contrast, deactivation of the initial Morakot vortex results in a completely different track and thus different rainfall distributions in Taiwan, as expected. Undoubtedly, the results highlight a dominant role of Morakot's intense vortex in regard to the extreme rainfall in Taiwan.

Ensemble forecasts may provide probabilistic features on track as well as rainfall (e.g., Fang et al. 2011). This appears to be an important but different issue. Without regard to probabilistic forecasts, we conducted several sensitivity experiments with respect to different factors including Taiwan terrain height, the Goni vortex and Typhoon Morakot. Thus, this study is more oriented for a systematic understanding of extreme rainfall in Taiwan. Based on the BDA method, we have also attempted to extend our understanding of the efficacy of monsoon intensity (e.g., Ge et al. 2010; Chien and Kuo 2011). However, we found that the current BDA modulation still cannot well preserve the monsoon strength for a long time, due to geostrophic adjustment to the mass field. The monsoon flow change is quite transient in response to such geostrophic adjustment. Thus, the contribution of the monsoon intensity to Morakot's extreme rainfall in Taiwan remains unexplored. The impacts of the monsoon intensity and moistening condition on this event should be investigated awaiting a robust method to construct a balanced large-scale monsoon flow for sensitivity tests.

Acknowledgements This study was supported by the National Science Council (NSC) in Taiwan.

\section{REFERENCES}

Bender, M. A., R. E. Tuleya, and Y. Kurihara, 1987: A numerical study of the effect of island terrain on tropical cyclones. Mon. Weather Rev., 115, 130-155, doi: 10.11 75/1520-0493(1987)115<0130:ANSOTE>2.0.CO;2. [Link]

Chang, S. W. J., 1982: The orographic effects induced by an island mountain range on propagating tropical cyclones. Mon. Weather Rev., 110, 1255-1270, doi: 10.11 75/1520-0493(1982)110<1255:TOEIBA >2.0.CO;2. [Link]

Chen, S. H., 2007: The impact of assimilating SSM/I and QuikSCAT satellite winds on hurricane Isidore simula- 
tions. Mon. Weather Rev., 135, 549-566, doi: 10.1175/ MWR3283.1. [Link]

Chen, Y. and C. Snyder, 2007: Assimilating vortex position with an ensemble Kalman filter. Mon. Weather Rev., 135, 1828-1845, doi: 10.1175/MWR3351.1. [Link]

Chiao, S. and Y. L. Lin, 2003: Numerical modeling of an orographically enhanced precipitation event associated with Tropical Storm Rachel over Taiwan. Weather Forecast., 18, 325-344, doi: 10.1175/1520-0434(2003) 018<0325:NMOAOE $>2.0 . \mathrm{CO} ; 2$. [Link]

Chien, F. C., Y. C. Liu, and C. S. Lee, 2008: Heavy rainfall and southwesterly flow after the leaving of Typhoon Mindulle (2004) from Taiwan. J. Meteorol. Soc. Jpn., 86, 17-41.

Chien, F. C. and H. C. Kuo, 2011: On the extreme rainfall of Typhoon Morakot (2009). J. Geophys. Res., 116, D05104, doi: 10.1029/2010JD015092. [Link]

Chou, C. B., C. Y. Huang, H. P. Huang, K. H. Wang, and T. C. Yeh, 2008: The analysis of typhoon structures using advanced microwave sounding unit data and its application to prediction. J. Appl. Meteorol. Climatol., 47, 1476-1492, doi: 10.1175/2007JAMC1577.1. [Link]

Dudhia, J., D. Gill, K. Manning, W. Wang, and C. Bruyere, 2005: PSU/NCAR Mesoscale Modeling System Tutorial Class Notes and User's Guide: MM5 Modeling System Version 3, available on the web site http://ww w.mmm.ucar.edu/mm5/documents/tutorial-v3-notes. $\underline{\mathrm{html}}$.

Fang, X., Y. H. Kuo, and A. Wang, 2011: The impact of Taiwan topography on the predictability of Typhoon Morakot's record-breaking rainfall: A high-resolution ensemble simulation. Weather Forecast., 26, 613-633, doi: 10.1175/WAF-D-10-05020.1. [Link]

Fujiwhara, S., 1921: The natural tendency towards symmetry of motion and its application as a principle in meteorology. Q.J.R. Meteorol.Soc., 47, 287-292, doi: 10.1002/qj.49704720010. [Link]

Ge, X., T. Li, S.Zhang, and M. Peng, 2010: What causes the extremely heavy rainfall in Taiwan during Typhoon Morakot (2009)? Atmos. Res. Lett., 11, 46-50, doi: 10. 1002/asl.255. [Link]

Hendricks, E. A., J. R. Moskaitis, Y. Jin, R. M. Hodur, J. D. Doyle, and M. S. Peng, 2011: Prediction and diagnosis of Typhoon Morakot (2009) using the Naval Research Laboratory's mesoscale tropical cyclone model. Terr. Atmos. Ocean. Sci., 22, 579-594, doi: 10.3319/ TAO.2011.05.30.01(TM). [Link]

Hong, C. C., M. Y. Lee, H. H. Hsu, and J. L. Kuo, 2010: Role of submonthly disturbance and 40-50 day ISO on the extreme rainfall event associated with Typhoon Morakot (2009) in southern Taiwan. Geophys. Res. Lett., 37, L08805, 1-6, doi: 10.1029/2010GL042761. [Link]

Hsiao, L. F., C. S. Liou, T. C. Yeh, Y. R. Guo, D. S. Chen,
K. N. Huang, C. T. Terng, and C. H. Chen, 2010: A vortex relocation scheme for tropical cyclone initialization in advanced research WRF. Mon. Weather Rev., 138, 3298-3315, doi: 10.1175/2010MWR3275.1. [Link]

Hsu, H. H., C. S. Lee, and C. C. Wu, 2010: Special report on Typhoon Morakot (2009). International Workshop on Typhoon Morakot (2009), Taipei, Taiwan, 25-26 March.

Huang, C. Y., Y. H. Kuo, S. H. Chen, and F. Vandenberghe, 2005: Improvements in typhoon forecasts with assimilated GPS occultation refractivity. Weather Forecast., 20, 931-953, doi: 10.1175/WAF874.1. [Link]

Jian, G. J., and C. C. Wu, 2008: A numerical study of the track deflection of Supertyphoon Haitang (2005) prior to its landfall in Taiwan. Mon. Weather Rev., 136, 598 -615, doi: 10.1175/2007MWR2134.1. [Link]

Krishnamurti, T. N., H. S. Bedi, and K. Ingles, 1993: Physical initialization using SSM/I rain rates. Tellus, 45A, 247-269, doi: 10.1034/j.1600-0870.1993.t01-3-00001. x. [Link]

Kurihara, Y., M. A. Bender, and R. J. Ross, 1993: An initialization scheme of hurricane models by vortex specification. Mon. Weather Rev., 121, 2030-2045, doi: 10.1175/1520-0493(1993)121<2030:AISOHM>2.0.C O;2. [Link]

Kurihara, Y., M. A. Bender, R. E. Tuleya, and R. J. Ross, 1995: Improvements in the GFDL hurricane prediction system. Mon. Weather Rev., 123, 2791-2801, doi: 10. 1175/1520-0493(1995)123<2791:IITGHP>2.0.CO;2. [Link]

Lee, C. S., Y. C. Liu, and F. C. Chien, 2008: The secondary low and heavy rainfall associated with Typhoon Mindulle (2004). Mon. Weather Rev., 136, 1260-1283, doi: 10.1175/2007MWR2069.1. [Link]

Leslie, L. M. and G. J. Holland, 1995: On the bogussing of tropical cyclones in numerical models: A comparison of vortex profiles. Meteorol. Atmos. Phys., 56, 101110, doi: 10.1007/BF01022523. [Link]

Lin, I. I., M. D. Chou, and C. C. Wu, 2011: The impact of a warm ocean eddy on Typhoon Morakot (2009): A preliminary study from satellite observations and numerical modelling. Terr. Atmos. Ocean. Sci., 22, 661-671, doi: 10.3319/TAO.2011.08.19.01(TM). [Link]

Lin, Y. L., D. B. Ensley, S. Chiao, and C. Y. Huang, 2002: Orographic influences on rainfall and track deflection associated with the passage of a tropical cyclone. Mon. Weather Rev., 130, 2929-2950, doi: 10.1175/1520-049 3(2002)130<2929:OIORAT>2.0.CO;2. [Link]

Lin, Y. L., S. Y. Chen, C. M. Hill, and C. Y. Huang, 2005: Control parameters for the influence of a mesoscale mountain range on cyclone track continuity and deflection. J. Atmos. Sci., 62, 1849-1866, doi: 10.1175/JAS 3439.1. [Link]

Liu, Y., D. L. Zhang, and M. K. Yau, 1997: A multiscale nu- 
merical study of Hurricane Andrew (1992). Part I: Explicit simulation and verification. Mon. Weather Rev., 125, 3073-3093, doi: 10.1175/1520-0493(1997)125<3 073:AMNSOH > 2.0.CO;2. [Link]

Matsumoto, J., 1989: Heavy rainfalls over east Asia. Int. J. Climatol., 9, 407-423, doi: 10.1002/joc.3370090407. [Link]

Pan, T. Y., Y. T. Yang, H. C. Kuo, Y. C. Tan, J. S. Lai, T. J. Chang, C. S. Lee, and K. H. Hsu, 2011: Improvement of statistical typhoon rainfall forecasting with ANNbased southwest monsoon enhancement. Terr. Atmos. Ocean. Sci., 22, 633-645, doi: 10.3319/TAO.2011.07. 04.01(TM). [Link]

Park, K. and X. Zou, 2004: Toward developing an objective 4DVAR BDA scheme for hurricane initialization based on TPC observed parameters. Mon. Weather Rev., 132, 2054-2069, doi: 10.1175/1520-0493(2004) $132<2054$ :TDAODB $>2.0 . \mathrm{CO} ; 2$. [Link]

$\mathrm{Pu}, \mathrm{Z}$. X. and S. A. Braun, 2001: Evaluation of bogus vortex techniques with four-dimensional variational data assimilation. Mon. Weather Rev., 129, 2023-2039, doi: 10.1175/1520-0493(2001)129<2023:EOBVTW>2.0. CO;2. [Link]

Ritchie, E. A. and G. J. Holland, 1993: On the interaction of tropical-cyclone-scale vortices. II: Discrete vortex patches. Q. J.R. Meteorol. Soc., 119, 1363-1379, doi: 10.1002/qj.49711951407. [Link]

Skamarock, W. C., J. B. Klemp, J. Dudhia, D. O. Gill, D. M. Barker, W. Wang, and J. G. Powers, 2005: A description of the advanced research WRF version 2. NCAR Technical Note NCAR/TN-468+STR, 100 pp.

Smolarkiewicz, P. K. and R. Rotunno, 1989: Low Froude number flow past three-dimensional obstacles. Part I: Baroclinically generated lee vortices. J. Atmos. Sci., 46, 1154-1164, doi: 10.1175/1520-0469(1989)046<11 54:LFNFPT>2.0.CO;2. [Link]

Tao, W. K., J. J. Shi, P. L. Lin, J. Chen, S. Lang, M. Y. Chang, M. J. Yang, C. C. Wu, C. Peters-Lidard, C. H. Sui, and B. J. D. Jou, 2011: High-resolution numerical simulation of the extreme rainfall associated with Typhoon Morakot. Part I: Comparing the impact of microphysics and PBL parameterizations with observations. Terr. Atmos. Ocean. Sci., 22, 673-696, doi: 10.3319/TAO.2011.08.26.01(TM). [Link]

Wang, D., X. Liang, Y. Zhao, and B. Wang, 2008: A comparison of two tropical cyclone bogussing schemes. Weather Forecast., 23, 194-204, doi: 10.1175/2007W AF2006094.1. [Link]

Wang, S. Y. and T. C. Chen, 2008: Measuring east Asian summer monsoon rainfall contributions by different weather systems over Taiwan. J. Appl. Meteorol. Climatol., 47, 2068-2080, doi: 10.1175/2007JAMC1821. 1. [Link]

Wu, C. C. and Y. H. Kuo, 1999: Typhoons affecting Tai- wan: Current understanding and future challenges. Bull.Amer. Meteorol.Soc., 80, 67-80, doi: 10.1175/15 20-0477(1999)080<0067:TATCUA > 2.0.CO;2. [Link]

Wu, C. C., T. H. Yen, Y. H. Kuo, and W. Wang, 2002: Rainfall simulation associated with Typhoon Herb (1996) near Taiwan. Part I: The topographic effect. Weather Forecast., 17, 1001-1015, doi: 10.1175/1520-0434(20 03)017<1001:RSAWTH $>2.0 . C O ; 2$. [Link]

Wu, C. C., K. H. Chou, Y. Wang, and Y. H. Kuo, 2006: Tropical cyclone initialization and prediction based on four-dimensional variational data assimilation. $J$. Atmos. Sci., 63, 2383-2395, doi: 10.1175/JAS3743.1. [Link]

Wu, C. C., K. K. W. Cheung, and Y. Y. Lo, 2009: Numerical study of the rainfall event due to the interaction of Typhoon Babs (1998) and the northeasterly monsoon. Mon. Weather Rev., 137, 2049-2064, doi: 10.1175/20 09MWR2757.1. [Link]

Wu, C. C., G. Y. Lien, J. H. Chen, and F. Zhang, 2010a: Assimilation of tropical cyclone track and structure based on the ensemble Kalman filter (EnKF). J. Atmos. Sci., 67, 3806-3822, doi: 10.1175/2010JAS3444.1. [Link]

Wu, C. C., C. Y. Huang, M. J. Yang, F. C. Chien, J. S. Hong, and T. H. Yen, 2010b: Typhoon Morakot (2009) and a special review on the current status and future challenge of tropical cyclone simulation. Chinese J. Atmos. Sci., 32, 99-134. (in Chinese)

Xiao, Q., X. Zou, and B. Wang, 2000: Initialization and simulation of a landfalling hurricane using a variational bogus data assimilation scheme. Mon. Weather Rev ., 128, 2252-2269, doi: 10.1175/1520-0493(2000)128<2 252:IASOAL>2.0.CO;2. [Link]

Xiao, Q., Y. H. Kuo, Y. Zhang, D. M. Barker, and D. J. Won, 2006: A tropical cyclone bogus data assimilation scheme in the MM5 3D-Var system and numerical experiments with typhoon Rusa (2002) near landfall. J. Meteorol.Soc. Jpn., 84, 671-689, doi: 10.2151/ jmsj.84.671. [Link]

Xiao, Q., L. Chen, and X. Zhang, 2009: Evaluations of BDA scheme using the Advanced Research WRF (ARW) Model. J. Appl. Meteorol. Climatol., 48, 680-689, doi: 10.1175/2008JAMC1994.1. [Link]

Yang, M. J., D. L. Zhang, and H. L. Huang, 2008: A modeling study of Typhoon Nari (2001) at landfall. Part I: Topographic effects. J. Atmos. Sci., 65, 3095-3115, doi: 10.1175/2008JAS2453.1. [Link]

Yang, M. J., T. C. Chen Wang, Y. Zhang, and C. Y. Weng, 2011: Momentum budget evolution of Typhoon Nari (2001) during the landfall process. Terr. Atmos. Ocean. Sci., 22, 595-612, doi: 10.3319/TAO.2011.05.31.01 (TM). [Link]

Yeh, T. C. and R. L. Elsberry, 1993a: Interaction of typhoons with the Taiwan orography. Part I: Upstream track deflections. Mon. Weather Rev., 121, 3193-3212, 
doi: 10.1175/1520-0493(1993)121<3193:IOTWTT>2. $0 . \mathrm{CO} ; 2$. [Link]

Yeh, T. C. and R. L. Elsberry, 1993b: Interaction of typhoons with the Taiwan orography. Part II: Continuous and discontinuous tracks across the island. Mon. Weather Rev., 121, 3213-3233, doi: 10.1175/1520-049 3(1993)121<3213:IOTWTT>2.0.CO;2. [Link]

Yen, T. H., C. C. Wu, and G. Y. Lien, 2011: Rainfall simulations of Typhoon Morakot with controlled translation speed based on EnKF data assimilation. Terr. Atmos.
Ocean. Sci., 22, 647-660, doi: 10.3319/TAO.2011.07. 05.01(TM). [Link]

Zou, X., W. Huang, and Q. Xiao, 1997: A User's Guide to the MM5 Adjoint Modeling System. NCAR Technical Note TN-437+1A, MMM division, 92 pp.

Zou, X. and Q. Xiao, 2000: Studies on the initialization and simulation of a mature hurricane using a variational bogus data assimilation scheme. J. Atmos. Sci., 57, 836860, doi: 10.1175/1520-0469(2000)057<0836:SOTIA $\mathrm{S}>2.0 . \mathrm{CO} ; 2$. [Link] 